\title{
Designing business model taxonomies - synthesis and guidance from information systems research
}

\author{
Frederik Möller ${ }^{1,2} \cdot$ Maleen Stachon $^{1} \cdot$ Can Azkan $^{2} \cdot$ Thorsten Schoormann $^{3} \cdot$ Boris Otto $^{1,2}$
}

Received: 21 March 2021 / Accepted: 1 October 2021 / Published online: 29 December 2021

(c) The Author(s) 2021

\begin{abstract}
Classification is an essential approach in business model research. Empirical classifications, termed taxonomies, are widespread in and beyond Information Systems (IS) and enjoy high popularity as both stand-alone artifacts and the foundation for further application. In this article, we focus on the study of empirical business model taxonomies for two reasons. Firstly, as these taxonomies serve as a tool to store empirical data about business models, we investigate their coverage of different industries and technologies. Secondly, as they are emerging artifacts in IS research, we aim to strengthen rigor in their design by illustrating essential design dimensions and characteristics. In doing this, we contribute to research and practice by synthesizing the diffusion of business model taxonomies that helps to draw on the available body of empirical knowledge and providing artifact-specific guidance for building taxonomies in the context of business models.
\end{abstract}

Keywords Taxonomy $\cdot$ Business model $\cdot$ Classification $\cdot$ Literature review $\cdot$ Business model taxonomy

JEL Classification A10

\section{Introduction}

Business models tell the story of how a business works (Magretta, 2002). Compelling business models are of great importance to achieve sustainable advantages as well as help novel technologies, products, and services to achieve economic success (Chesbrough, 2010; Gambardella \& McGahan, 2010). To make the complexity of a business model more graspable, classification approaches can be employed that provide distinguishable business model types (BadenFuller \& Morgan, 2010; Kamprath \& Halecker, 2012; Lambert, 2006b), enabling analyzing and developing business models (Lambert, 2015; Lund, 2013). So-called business model taxonomies ${ }^{1}$ are among the dominant forms of such classifications (Nielsen et al., 2018) that have high merit

Responsible Editor: Fabio Lobato.

Frederik Möller

frederik.moeller@tu-dortmund.de

1 TU Dortmund University, Dortmund, North Rhine-Westphalia, Germany

2 Fraunhofer ISST, Dortmund, Germany

3 University of Hildesheim, Hildesheim, Germany for theory and practice because they allow for advancing scientific understanding and enable finding new combinations and stimulating innovation (Lambert, 2015; Paukstadt et al., 2019b; Remane et al., 2016). These taxonomies respond to the need to create an empirical understanding of how the business model concept itself is used and how business models work, demanding "real-life examples to study" (Baden-Fuller \& Morgan, 2010, p. 163). To do so, they act as storage systems for empirical knowledge about business models (Lüdeke-Freund et al., 2018; Rich, 1992).

However, the specifics of designing empirical classifications of business models are an under-researched field that require structure and rigor (Fielt, 2013; Groth \& Nielsen, 2015; Lambert, 2015). While there have been studies investigating empirical research in business models, to the best of our knowledge, there are no studies that explicitly analyze the phenomenon of business model taxonomies (Lambert \& Davidson, 2013), leaving the aforementioned potentials for business model design rather untapped. To bridge this gap, this study focuses on two areas, namely (1) the diffusion of business model taxonomies with regards to the industry

${ }^{1}$ Being aware of authors differentiating between classification types (e.g., Bailey (1994)), this paper follows business model literature that uses taxonomy as empirical classifications and typology as conceptual classifications (e.g., Lambert (2015)). 
and/or technology and (2) options for the design of such taxonomies. Next, both areas are described in more detail.

Visualizing taxonomies as morphological fields allows making conclusions about the Gestalt of the phenomenon, i.e., its configuration (Ritchey, 1998). Thinking in configurations is valuable for business model design because most business models recombine available patterns (Gassmann et al., 2017). For this reason, corresponding configurations (i.e., taxonomies) should be available for many design situations. To this day, we observe that business model taxonomies emerge from different technologies and in domains as diverse (DaSilva \& Trkman, 2014; Zott et al., 2010, 2011), such as mobility (Lembcke et al., 2020; Remane et al., 2016), logistics (Möller et al., 2020), and FinTech (Eickhoff et al., 2017). Thereby, other established industries, like fashion and automotive, lack empirical analysis in the form of taxonomies. However, understanding business models and leveraging their potential across industry and technology is a vital issue for economic success, as "a better business model will often beat a better idea or technology" (Chesbrough, 2007, p. 12). In domains not addressed by taxonomies, academics and practitioners are less supported in getting inspiration and possible configurations from available best practice examples. Since the business model has both high utility in general and a focus on an industry-scale (Groth \& Nielsen, 2015), we asked: What is the diffusion of business model taxonomies in terms of industrial sectors and technologies? (RQ1)

In addition to the heterogeneity of domains and technologies addressed, we can observe an inconsistent way of how such taxonomies are designed, indicating a need for further methodological guidance. Generally, business model taxonomies vary across context-specific (design) dimensions, which, if carefully analyzed, advances the understanding of how they should be created (Fielt, 2013). As those taxonomies are an emerging artifact and of high importance for business model research (Groth \& Nielsen, 2015; Lambert, 2015), we propose a meta-study that examines current practices to guide their future design. Accordingly, we asked: How to guide the design of business model taxonomies? (RQ2)

In pursuing to answer our RQs, we perform two main phases. Firstly, based on a literature sample, we extract design options and examine how researchers build business model taxonomies to guide the future design of this type of taxonomies. Secondly, we show industries and technologies addressed in our sample to quantify the current degree of the taxonomy's coverage and identify white spots for future research endeavors.

The article is structured as follows. Next, we illustrate the background of business models and taxonomies. We afterward explain our research design, consisting of a structured literature review and a taxonomy development. Based on this, we present our design variables for business model taxonomies. We then discuss the results and identify implications for the broader field of business model taxonomies and reflect on their design's best practices. Lastly, we highlight contributions, state limitations, and illustrate avenues for further research.

\section{Background}

\section{Business models}

Business models have become a viable object of interest in IS (Veit et al., 2014) and in-company practice (CasadesusMasanell \& Ricart, 2011). Although the term business model is occasionally entwined with adjacent terms (Gordijn et al., 2000; Seddon et al., 2004), it is located at the intersection of the higher-order business strategy and the operationalizable business processes (Al-Debei \& Avison, 2010; AlDebei et al., 2008). Despite a rich body of literature, there is still no standard definition of the business model concept (Burkhart et al., 2011); Teece (2018, p. 41) even argues that there are so many definitions "of a business model, as there are business models." Subsequently, researchers list and compare several definitions (e.g., Zott et al. (2010) or Fielt (2013)) and business model components (e.g., Morris et al. (2005) or Shafer et al. (2005)).

Despite having no single definition, the business model concept can have three major interpretations (Massa et al., 2017). Firstly, business models as a 'cognitive/logistic schema', which presumes that managers do not hold systems in their minds when they make decisions but images of such systems shaped by their own cognitive frames. Secondly, business models as 'formal conceptual representations'. In contrast to implicit and unspoken schemas, business models are explicated to articulate the complexity of business logic. This interpretation understands a business model as a conceptual blueprint of the company's logic (Amit \& Zott, 2001; Osterwalder et al., 2005). Here, the business model canvas (Osterwalder, 2004; Osterwalder \& Pigneur, 2013) enjoys widespread recognition (Spieth et al., 2014). Thirdly, business models as 'attributes of real firms'. In this interpretation, business models are seen as empirical phenomena or attributes determined "by empirically classifying real-world manifestations of organizations" (Massa et al., 2017, p. 76). That can be supported by, for instance, business archetypes and concepts like 'freemium' business models. In this study, we focus on the third interpretation in particular because this allows understanding how firms do business and support the design of business models utilizing empirical attributes and archetypes.

In recent years, the business model literature has shifted to analyzing digital business models that primarily build 
upon digital technologies (Bock \& Wiener, 2017; Dos Santos et al., 2014; Otto et al., 2015; Veit et al., 2014). For example, data-driven business models explicitly leverage data as the key resource (Hartmann et al., 2016; Schüritz et al., 2017), and platform business models focus on generating network effects (Asadullah et al., 2018; Giessmann \& Legner, 2016). These exemplary developments illustrate the demand for understanding new (digital) business models and their underpinning fast-evolving technologies, which can be supported by empirical taxonomies.

\section{Business model taxonomies}

Business model classifications - taxonomies, typologies, types, and patterns - are an integral part of business model research (Gassmann et al., 2017; Osterwalder et al., 2005; Pateli \& Giaglis, 2004). Typically, business model classifications produced deductively derived typologies that did not have an empirical basis but sought to formulate idealized types of businesses (Baden-Fuller \& Morgan, 2010; Lambert, 2006a, 2015). Following Weber (1949), idealized types refer to a high abstraction of detail, then to distinguish between detailed empirical objects. Hence, the first business model classifications only covered a few dimensions, often two, and created descriptive labels (e.g., Timmers (1998), Rappa (2004), Kamoun (2008)).

A body of literature on business model taxonomies has emerged that predominantly leverages empirical data to generate taxonomies of business models and analyze them more intensively by developing clusters and archetypes. For instance, Remane et al. (2016) identify car-sharing business models, clusters, and archetypical patterns; Eickhoff et al. (2017) did this for FinTech start-ups (for an overview of business model taxonomies, see Appendix 1). Often, these business model taxonomies gather data using publicly available data sources via desk research based on the notion that "(...) business model elements are often quite transparent and (in principle) easy to imitate (...)" (Teece, 2010, p. 179). The clusters host individual business models that are highly similar to each other yet, highly dissimilar to business models in different clusters. They are the foundation to identify business model patterns, which are reoccurring configurations to solve reoccurring problems (Rudtsch et al., 2014). Rather than being merely descriptive, the purpose of patterns is to help their users design new business models and break cognitive barriers (Remane et al., 2017b). Patterns that implicate foundational configurations, i.e., those that are representative and used for imitation, are archetypical patterns or archetypes (Johnson, 1994), which, in business models, are highly representative examples (Fielt, 2013). Our analysis shows that there are numerous ways to develop business model taxonomies that diverge in method, visualization, and other design parameters, which motivates this study's systematic inquiry to support business model taxonomy design.

\section{Research design}

In line with our overall goal of providing a sound overview of available business model taxonomies and guide their future design, two phases are performed, namely (1) reviewing the literature to obtain a sample of empirically derived business model taxonomies and (2) examining options for business model taxonomy design.

\section{Phase 1: structured literature review}

To obtain empirical data, we conducted a structured literature review by following the guidelines of Webster and Watson (2002) (see Appendix 4 for details). We define the literature search scope for articles presenting business model taxonomies as their contribution or articles dealing with the conceptual underpinnings. The latter objective requires a backward search, as these types of articles are usually referenced in papers presenting corresponding taxonomies. Based on this, we constructed a nexus of literature that we divide according to taxonomy building approaches (i.e., conceptual-to-empirical or empirical-to-conceptual iterations). We used common databases in IS research, i.e., AISeL, Scopus, and Google Scholar. Although an obvious limitation of the review is that one might miss an article (Webster \& Watson, 2002), we strived for an exhaustive sample for taxonomy building (Cooper, 1988) with the following filtering criteria. To ensure the inclusion of quality papers, we aimed for $V H B^{2}$ ranked journals and conference proceedings in IS (Weking et al., 2020a). Thus, we included ECIS, ICIS, PACIS, AMCIS, WI, and HICSS. We made exceptions to that paradigm if $V H B$ does not cover high-quality papers but fits through the scope, quality, and method (e.g., Thiebes et al. (2020)).

Additionally, we only considered papers that produce business model taxonomies in a non-trivial way and provide sufficient, transparent information about their design and results. Predominantly, we focus on the term taxonomy to gather empirical classifications (see above). Subsequently, we do not include papers in our sample that do not explicitly reference empirical or literature-based taxonomy design, e.g., mainly qualitatively designed morphologies (e.g., Azkan et al. (2020b) or Labes et al. (2015)). Lastly, we opted only to include peer-reviewed literature in journals and conference proceedings (Levy \& Ellis, 2006) and one book publication (Nagel \& Kranz, 2020; Nagel et al., 2019).

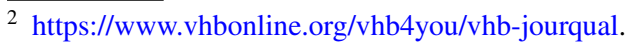


Table 1 Overview of literature search

\begin{tabular}{llll}
\hline Search String & Database & Results & Included \\
\hline $\begin{array}{c}\text { "Business Model Taxonomy" } \\
\text { OR "Business Model Clas- } \\
\text { sification" }\end{array}$ & AISeL (Title and Abstracts) & 66 & 14 \\
$\begin{array}{c}\text { TITLE-ABS-KEY ("business } \\
\text { model" AND "Taxonomy") }\end{array}$ & Scopus (Title and Abstracts) & 251 & 24 \\
& $\begin{array}{c}\text { Final Sample (no duplicates, filtering, forward \& backward } \\
\text { search*) }\end{array}$ & $\sum=31^{1}$ \\
\hline
\end{tabular}

See Appendix 1 for entire sample
Table 1 summarizes databases, search terms, and the final sample resulting from the forward \& backward search. We used Google Scholar to cross-validate our findings and for backward and forward searches. We stopped our literature review as soon as all researchers (having researched each database individually) could not find additional articles (Leedy \& Ormrod, 2014; Randolph, 2009).

We excluded papers that did not fit this study's scope: Purely conceptual papers (see Lambert (2006a), Lambert (2006b), Lambert (2015), Lambert and Davidson (2013), Groth and Nielsen (2015), or Kamprath and Halecker (2012)); papers with a different focus, such as taxonomies for business model development tools (see Szopinski et al. (2017) or Szopinski et al. (2019a)), classifications of literature (see Burkhart et al. (2011)), taxonomies with other analytical objects (see Berger et al. (2018) or Hanelt et al. (2015)) or other classification types (see Endres et al. (2019), Breitfuss et al. (2019), or Abdollahi and Leimstoll (2011)).

The resulting sample (from 2010 to 01/2021) shows a substantial increase in publications on business model taxonomies since 2016; between 2010 and 2015, there was only one empirical business model taxonomy. Since 2016, each year either produced more or the same number of business model taxonomies than the previous one, indicating a rise in interest. 2020 is the peak year for publications proposing business model taxonomies. Figure 1 shows each publication outlet and the corresponding number of publications relevant to this study. Most taxonomies $(n=23)$ originate in IS outlets (ICIS, ECIS, HICSS).

Two researchers and one research assistant independently analyzed each paper by constructing a concept matrix (Webster \& Watson, 2002) and discussed their findings in regularly scheduled meetings. The final matrix is a product of consensus. The papers varied in transparency and information; thus, determining some dimensions required judgment (Saldaña, 2015; Sipe \& Ghiso, 2004). For example, we manually analyzed the taxonomy and agreed on a categorization if the papers did not indicate whether characteristics are mutually exclusive. ${ }^{3}$

\section{Phase 2: taxonomy building and evaluation}

To derive design options for business model taxonomies, this study follows the de facto standard in taxonomy development, the method of Nickerson et al. (2013), which replaced prior existing ad hoc-approaches (Oberländer et al., 2019; Szopinski et al., 2019b). As the first step, one must determine a meta-characteristic, which is both the superordinate purpose of the taxonomy and the ultimate starting point from which all subordinate elements must be derived. In our case, the meta-characteristic reads as follows: Provide design options that guide future development of business model taxonomies (purposes); designers of business model taxonomies, practitioners, and academics interested in business model classifications (target group).

Afterward, ending conditions need to be specified, which terminate the iterative taxonomy building process. Nickerson et al. (2013) recommend five subjective ending conditions and eight objective ending conditions that we adopted in our building process. In the next step, approach, one must choose between either following the conceptual-to-empirical or empirical-to-conceptual path to generate/revise a taxonomy. The conceptual-to-empirical approach mirrors essentialist, deductive reasoning in finding dimensions and characteristics, while the empirical-to-conceptual approach relies on inductive, empiricist rationales (Lambert, 2015). Finally, the process is repeated until the designer reaches theoretical saturation, i.e., until no taxonomy manipulation is necessary (Appendices 2 and 3).

\footnotetext{
3 Other = Book publication of Nagel and Kranz (2020).

Non-IS Journals: International Journal of Production Economics, Journal of Medical Internet Research, European Management Journal, Journal of Business Strategy, International Journal of Innovation Management, International Journal of Operations \& Production Management.
} 
Fig. 1 Distribution of papers across years (left-hand side; collection ended in 01/2021) and outlets (right-hand side)
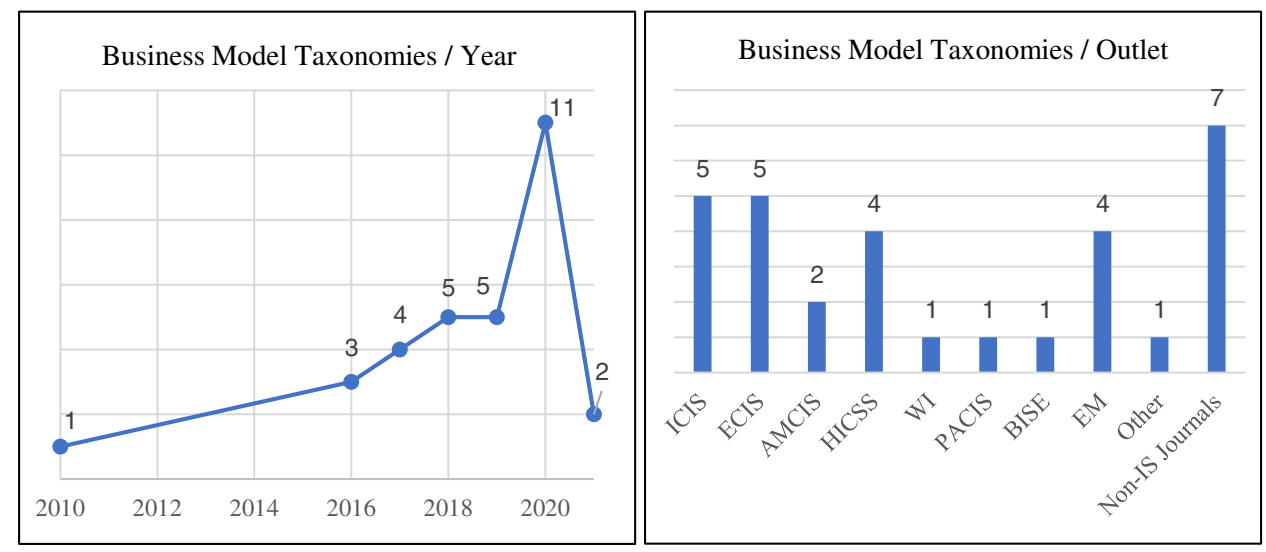

ICIS = International Conference on Information Systems, ECIS = European Conference on Information Systems, AMCIS $=$ Americas Conference on Information Systems, HICSS $=$ Hawaii International Conference on System Sciences, WI = International Conference on Wirtschaftsinformatik, PACIS $=$ Pacific-Asia Conference on Information Systems, $\mathrm{BISE}=$ Business \& Information Systems Engineering, EM = Electronic Markets.

\section{Taxonomy building - iterations (Approach)}

The taxonomy in this study required three iterations to reach its final state (see Table 2). In the $1^{\text {st }}$ iteration, we chose the conceptual-to-empirical approach and strived to identify conceptual underpinnings that could give us initial dimensions and characteristics. Secondly, as our final sample contains 31 papers presenting business model taxonomies, we divided it into 16 papers for the $2^{\text {nd }}$ iteration and 15 papers for the $3^{\text {rd }}$ iteration. The $2^{\text {nd }}$ iteration is empirical-to-conceptual, which we use to develop the conceptually derived initial dimensions and characteristics. The $3^{\text {rd }}$ iteration, also empirical-to-conceptual, completes the full analysis of the sample.

$\mathbf{1}^{\text {st }}$ Iteration: The basis for determining initial conceptual dimensions and characteristics is the foundational literature on business model taxonomies and taxonomies in general. Therefore, we create a literature corpus consisting of (1) papers that report on original business model taxonomies (e.g., Remane et al. (2016) or Paukstadt et al. (2019a)) and (2) papers that discuss their theoretical underpinnings either focused on business model taxonomies or taxonomies in general (e.g., Lambert (2015), Groth and Nielsen (2015), or Glass and Vessey (1995)). As a result of this analysis, we could identify a set of relevant elements.

For example, Glass and Vessey (1995) discussed that a taxonomy must be tailored to a specific purpose or be generally applicable, which has implications for the conceptual broadness of dimensions and characteristics. A mutually exclusive, dichotomous division between either generating a specific or general taxonomy seems sensible for any business model taxonomy (McKelvey, 1978). General taxonomies should be applicable on a broader scale and require more general and abstract characteristics, while specific taxonomies should thematize conceptually narrow characteristics (Glass \& Vessey, 1995; Hanelt et al., 2015).

Another example is Lambert's (2015) proposition, which argues for general taxonomies spanning multiple industries that enable the derivation of more generally applicable patterns. Contrarily, Kamprath and Halecker (2012, p. 6) highlight the notion of industry-specific business model classifications, as these allow "(...) greater insights in these particular sectors". Yet, as we can see, looking at seminal articles in the field (e.g., see Hartmann et al. (2016)), there is also merit in generating generic business model taxonomies that do not focus on a particular industry but take a

Table 2 Overview of taxonomy building iterations

\begin{tabular}{|c|c|c|c|}
\hline Iteration & Approach & Sample & Rationale \\
\hline 1 & Conceptual-to-Empirical & - & $\begin{array}{l}\text { The literature provides existing knowledge about taxonomies in general and business model } \\
\text { taxonomies. For that reason, it is appropriate first to incorporate conceptual knowledge from the } \\
\text { underlying literature to achieve both a high degree of rigor and connectedness to theory }\end{array}$ \\
\hline 2 & Empirical-to-Conceptual & 16 & $\begin{array}{l}\text { The dimensions and characteristics defined in the previous iteration are tested against empirical } \\
\text { objects, i.e., business model taxonomies from the literature. We divided the sample to have an } \\
\text { initial empirical set of objects for design and, at least, a second group to validate the findings } \\
\text { against more objects }\end{array}$ \\
\hline 3 & Empirical-to-Conceptual & 15 & $\begin{array}{l}\text { Another empirical-to-conceptual iteration is necessary to test the finding from the } 2^{\text {nd }} \text { iteration and } \\
\text { refine dimensions and characteristics }\end{array}$ \\
\hline
\end{tabular}


broad look, at the concept itself. Of course, choosing either path has implications for the degree of generalizability, i.e., either on an industry level or a general, conceptual level (Lambert \& Montemari, 2017). However, as both avenues seem reasonable, a dimension for business model taxonomy design should reflect whether it is supposed to be industryindependent or tailored to a particular industry.

Both Szopinski et al. (2020) and Oberländer et al. (2019) highlight that there is a range of visualization options for taxonomies, morphological fields, tables, matrices, mathematical sets, hierarchies, visual, or textual, which seem suitable characteristics to emerge from the $1^{\text {st }}$ iteration. Additionally, Nickerson et al.'s (2013) method is the de facto standard, which would indicate that it is a central characteristic (Oberländer et al., 2019; Szopinski et al., 2019b). To ensure a dimension's dichotomy, there is a need for providing additional development methods.

Summarizing, in the $1^{\text {st }}$ iteration, we deduced dimensions for visualization, depth of analysis, industry scope, and development method. In Appendix 5, we provide details of each iteration.

$\mathbf{2}^{\text {nd }}$ Iteration: The next iteration inductively generates dimensions and characteristics from 16 papers. We could not find an example that visualizes taxonomies as mathematical sets or graphical illustrations in terms of visualization; some authors use mathematical sets to explain the development of their taxonomies. Complementarily to industry sectors, papers also focus on specific technologies. We integrated the dimension of technology scope that distinguishes between a technology-centered or a generic focus. If articles visualize the taxonomy as morphologies, they often use metadimensions. Therefore, we include the binary status of using meta-dimensions in business model taxonomy as a dimension. As an additional development method, we found, for example, Täuscher and Laudien (2017), who use a numerical approach to taxonomy design (see Appendix 5).

$\mathbf{3}^{\text {rd }}$ Iteration: After analyzing the remaining 15 papers, there are no significant taxonomy changes (e.g., changing the name of the dimension meta-dimension to theoretical lens). We opted to extend the taxonomy's utility and structure by classifying each dimension into a higher-order group of meta-dimensions and order them in a sequence. Usually, these meta-dimensions would act as a conceptual lens that allows the user to analyze empirical data through a specific conceptual framework. In our case, we use meta-dimensions to bring additional structure and clarity into the taxonomy.

We have abstracted four meta-dimensions: Data includes all dimensions outlining the underlying object of analysis, how data is collected, how the data is sampled, and whether a theoretical lens for their study is applied. Development subsumes dimensions relevant to construct the business model taxonomy structurally. It specifies what method is applied to generate the taxonomy, whether the taxonomy analyzes a specific technology or industry, and the conceptual depth. These dimensions are highly relevant in shaping how the data is analyzed and to what extend the dimensions and characteristics are specific and conceptually narrow or generic and very broad. Representation contains dimensions for the taxonomy's visual construction, including the configuration of the visualization style for the taxonomy (e.g., morphological field or hierarchies). Also, it consists of the dimension exclusivity, which describes whether the dimensions have mutually exclusive characteristics. Analysis focuses on further processing of taxonomical results. This processing including the dimension further application (different outcome based on the taxonomy), clustering tool, clustering algorithm (e.g., Ward (1963)).

Additionally, in the $3^{\text {rd }}$ iteration, we introduced the notion of exclusivity of characteristics, which we determined for every dimension through discussion amongst the authors. The final taxonomy is as follows:

$\mathrm{T}_{\text {Final }}=\{$

$\mathrm{MD}_{1}$ (Data) \{

$\mathrm{D}_{1}$ (Object of Analysis) I $\mathrm{C}_{1}$ (Start-Ups, Incumbents, No Differentiation) $\mid \mathrm{EX}=\{\mathrm{N}\}$.

$\mathrm{D}_{2}$ (Data Collection) I $\mathrm{C}_{2}$ (Public Data Analysis, Literature Review, Hybrid) $\mid \mathrm{EX}=\{\mathrm{Y}\}$.

$\mathrm{D}_{3}$ (Data Sampling) $\mid \mathrm{C}_{3}$ (Random, Selective/Comprehensive) $\mid \mathrm{EX}=\{\mathrm{Y}\}$.

$\mathrm{D}_{4}$ (Theoretical Lens) $\mid \mathrm{C}_{4}$ (Yes, No) $\left.\mid \mathrm{EX}=\{\mathrm{Y}\}\right\}$,

$\mathrm{MD}_{2}$ (Development) \{

$\mathrm{D}_{5}$ (Development Method) । $\mathrm{C}_{5}$ (Nickerson et al. (2013), Numerical, MDS, Grounded Theory, Ad Hoc) I $\mathrm{EX}=\{\mathrm{Y}\}$.

$\mathrm{D}_{6}$ (Industry Scope) $\mid \mathrm{C}_{6}$ (Industry-Specific, Generic) I $\mathrm{EX}=\{\mathrm{Y}\}$.

$\mathrm{D}_{7}$ (Technology Scope) $\mid \mathrm{C}_{7}$ (Technology-Specific, Generic) $\mid \mathrm{EX}=\{\mathrm{Y}\}$.

$\mathrm{D}_{8}$ (Depth of Analysis) $\mid \mathrm{C}_{8}$ (Narrow, Wide) । $\mathrm{EX}=\{\mathrm{Y}\}\}$,

$\mathrm{MD}_{3}$ (Representation) \{

$\mathrm{D}_{9}$ (Exclusivity) $\mid \mathrm{C}_{9}$ (Mutual, Partial, None) । $\mathrm{EX}=\{\mathrm{Y}\}$.

$\mathrm{D}_{10}$ (Visualization) $\mid \mathrm{C}_{10}$ (Morphological field, Hierarchy, Table/Matrix) $\mid \mathrm{EX}=\{\mathrm{Y}\}\}$,

$\mathrm{MD}_{4}$ (Analysis) \{ 
Table 3 Design options for business model taxonomies and three exemplary applications

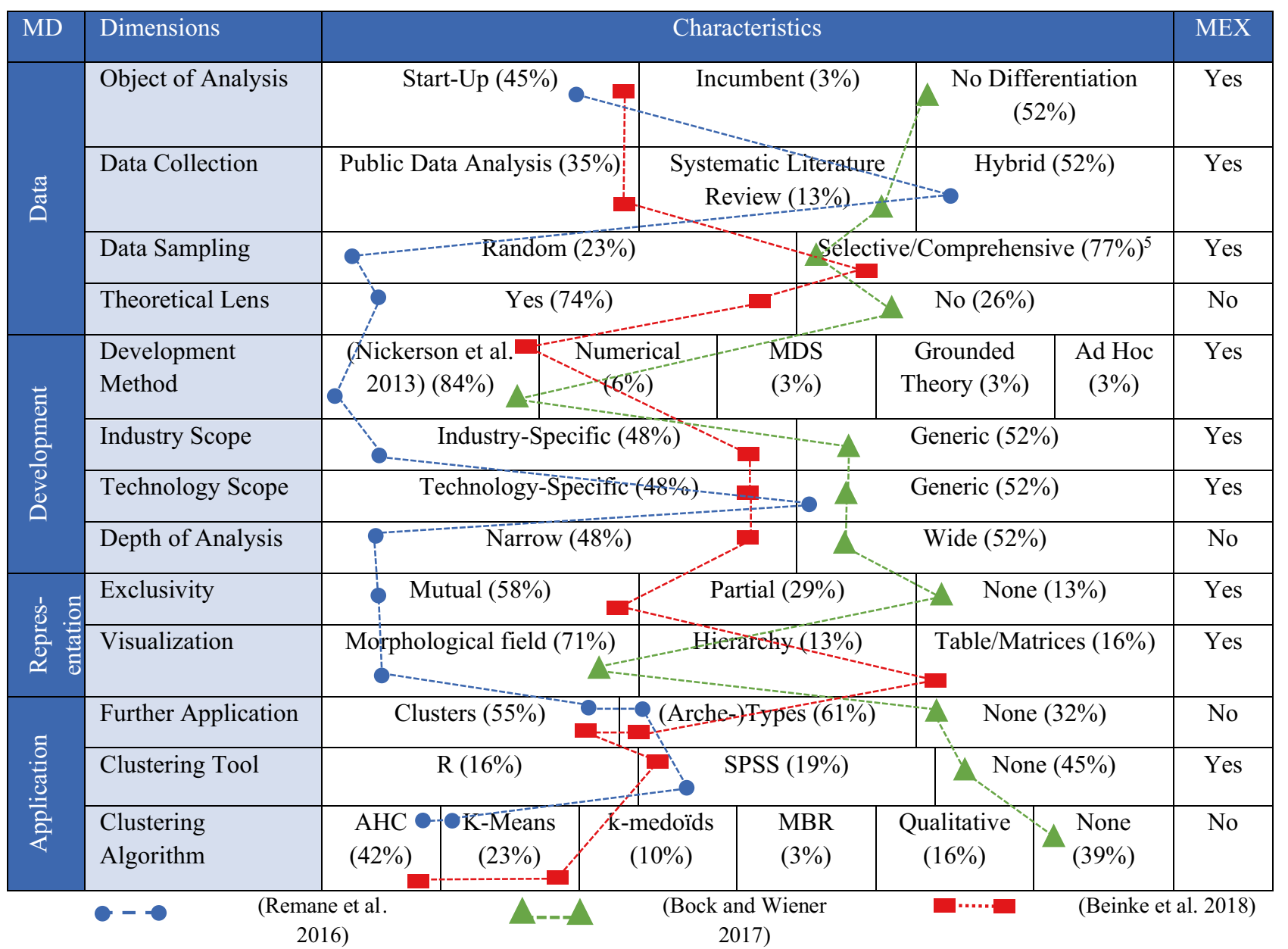

Some dimensions exceed $100 \%$ if multiple characteristics could be selected or fall below $100 \%$ if not all characteristics could be filled out. $\mathrm{MD}=$ Meta-Dimension, $\mathrm{MEX}=$ Exclusivity, $\mathrm{AHC}=$ Agglomerative Hierarchical Clustering. For a definition of each characteristic, see Appendix 2.

$\mathrm{D}_{11}$ (Further Application) I $\mathrm{C}_{11}$ (Clusters, (Arche-) types, None) $\mid \mathrm{EX}=\{\mathrm{N}\}$.

$\mathrm{D}_{12}$ (Clustering Tool) $\mid \mathrm{C}_{12}$ ( $\mathrm{R}$, SPSS, None) । $\mathrm{EX}=\{\mathrm{Y}\}$.

$\mathrm{D}_{13}$ (Clustering Algorithm) I $\mathrm{C}_{13}$ (AHC, K-Means, k-medoïds, MRB, Qualitative, None) $\mid \mathrm{EX}=\{\mathrm{Y}\}\}\}$

\section{Taxonomy building - ending conditions}

Taxonomies, per se, are never finished but can only achieve a satisfactory state in that they are useful in depicting the objects they were meant to show (Bock \& Wiener, 2017; Nickerson et al., 2013). We follow standard practice in taxonomy design and use the ending conditions from Nickerson et al. (2013) to indicate the building process's termination and indicate minimum requirements for valid and useful taxonomies. All 31 business model taxonomies could be classified in the final iteration in terms of objective ending conditions. While minor changes were required in the last iteration (e.g., removing characteristics introduced in the $1^{\text {st }}$ iteration, which could not be verified empirically), no significant manipulations were necessary. Additionally, all dimensions and characteristics are unique and occupied by at least one object, ensuring that no dimension or characteristic is redundant or empty. Regarding the subjective ending conditions, we argue that our taxonomy consisting of thirteen dimensions is concise. The sheer visual representation is not overwhelming, and the number of dimensions and characteristics is in line with similar taxonomies (Oberländer et al., 2019). The taxonomy is robust, as it can be used to differentiate between individual objects, which results, for example, in the creation of Table 3. The taxonomy has a logical flow (see Table 3) and describes the central design variables in the design of business model taxonomies in detail. It is comprehensive and extendible, as all objects could be classified in the taxonomy, yet, as the iterations show, the extension 
is intuitive and easy to do. Lastly, our taxonomy is explanatory as it describes how business model taxonomies differ and guides researchers as to which design parameters they consider in their designs ${ }^{4}$.

\section{Taxonomy evaluation}

To further indicate our taxonomy's usefulness in guiding business model designers, we follow Szopinski et al. (2019b) and configure an evaluation according to the subject, object, and method. Thereby, we differentiate between an internal and external part. The first part is an internal evaluation in which the authors analyze the taxonomy's applicability using illustrative examples. All authors have prior experience in designing business model taxonomies. Using examples to illustrates the applicability of taxonomies is a common practice in taxonomy research (e.g., Bock and Wiener (2017) or Remane et al. (2017a)) and design science research (Peffers et al., 2012). We took three sample objects randomly and illustrated how they can be classified with our taxonomy (see Table 3). Subsequently, we can demonstrate that the taxonomy achieves its purpose to classify business model taxonomies.

The second part aims to extend the evaluation beyond the author team to knowledgeable subjects. In line with our primary target group (see meta-characteristic), we held a group discussion with researchers from university and applied research. All five participants have prior knowledge of creating taxonomies. One participant is also knowledgeable in the business models domain and is explicitly familiar with designing business model taxonomies. Each participant was introduced to the taxonomy and an information sheet with definitions of each dimension and characteristic. We split the participants into two groups and asked them to classify four randomly selected business model taxonomies. After both groups had finished, we held a group discussion on the taxonomy's potentials. Issues raised regarded qualitative assessed characteristics. For example, the participants highlighted that the dimension conceptual depth should not be mutually exclusive because some taxonomies are not categorizable as either narrow or wide. The distinction between the dominant approach to collect data was unclear, as the papers varied greatly in their degree of using prior literature. Some papers clearly outline systematic literature review approaches, while others shortly indicate that the existing literature corpus influences taxonomy design. Lastly, in the dimension data sampling, the participants highlighted that

\footnotetext{
${ }^{4}$ According to our evaluation, the characteristic should be split into selective and comprehensive. As it was not possible to identify the exact characteristic in enough papers, we did not split the characteristic in our data sample, yet, recommend for users of our taxonomy to choose one of both approaches.
}

the characteristic selective/comprehensive should be split into two different characteristics. We followed that advice, yet, we did not differentiate in our numerical analysis as determining both characteristics in the paper proved to be too blurry. We asked all participants to provide us with feedback on whether the taxonomy would help them design their taxonomies, to which all agreed. Overall, the usefulness for novice researchers to develop (business model) taxonomies was stressed. Finally, the participants highlighted the need to include strategies for evaluation. Yet, following Szopinski et al. (2019b), most papers do not actively evaluate taxonomies. We do, however, not see a taxonomy decision but rather a recommendation to choose suitable evaluation strategies.

\section{Results: design options for business model taxonomies}

Table 3 illustrates the final taxonomy for the design of business model taxonomies as a morphological field. We chose that type of visualization because it enables intuitive insights into how such taxonomies work (Ritchey, 1998). Instead of merely classifying taxonomies, we dedicatedly wanted to analyze their design phenomenology, i.e., their forms and possible morphological design configurations (Cross, 1999; Fiedler et al., 1996). Moreover, we structured the design options through higher-order theoretical lenses (Niederman \& March, 2019), so-called meta-dimensions (see below). These meta-dimensions are ordered according to the potential sequence of building business model taxonomies, starting from obtaining data to applying a (completed) taxonomy.

To provide further guidance on operationalizing the design options, Table 4 outlines key questions that researchers can use while designing their business model taxonomies. Simultaneously, these guiding questions represent our rationales for selecting dimensions and our understanding of them.

\section{Meta-dimension: data}

The dimension object of analysis refers to whether authors consider a specific focus for their business model taxonomies (start-up and incumbent firm) or take a rather holistic view and do not make any differentiation.

Data collection describes approaches to gather the underlying data and thereby differentiates three characteristics for determining business model elements through an empirical analysis of publically available data, a systematic review of literature, or a hybrid approach combining both. The characteristic hybrid also includes interviews, which few papers used to collect empirical samples or insights into taxonomy building (e.g., see Passlick et al. (2021)). As it is not a 
Table 4 Guiding questions for business model taxonomy design

\begin{tabular}{|c|c|c|}
\hline Meta-dimension & Dimension & Guiding question \\
\hline \multirow[t]{4}{*}{ Data } & Object of Analysis & Which objects does the taxonomy examine? \\
\hline & Data Collection & What is the approach to collect the data? \\
\hline & Data Sampling & How are the data sampled? \\
\hline & Theoretical Lens & $\begin{array}{l}\text { Does the taxonomy use a business model framework as a theo- } \\
\text { retical lens to analyze the data? }\end{array}$ \\
\hline \multirow[t]{4}{*}{ Development } & Development Method & Which method is used to develop the taxonomy? \\
\hline & Industry Scope & Is the taxonomy specific for an industry? \\
\hline & Technology Scope & Is the taxonomy specific for a technology? \\
\hline & Depth of Analysis & What is the level of conceptual detail of the taxonomy? \\
\hline \multirow[t]{2}{*}{ Representation } & Exclusivity & Are the dimensions mutually exclusive? \\
\hline & Visualization & How is the taxonomy visualized? \\
\hline \multirow[t]{3}{*}{ Application } & Further Application & Is the taxonomy used for developing clusters and/or archetypes? \\
\hline & Clustering Tool & Which cluster tool, if any, was used to cluster the data? \\
\hline & Clustering Algorithm & Which cluster algorithm, if any, was used to cluster the data? \\
\hline
\end{tabular}

stand-alone characteristic and purely interview-based qualitative taxonomies would be out of our scope, we subsume interviews under hybrid. Usually, in the latter case, literature is the starting point to build initial dimensions extended with empirical data in subsequent iterations. If the taxonomy is purely based on literature, there is no additional empirical analysis of business model data.

The dimension data sampling dichotomously distinguishes between a random approach (i.e., choosing a random sub-sample of a larger corpus that might be too large to analyze comprehensively) and selective sampling (i.e., identifying suitable objects either wholly or representatively). Through our evaluation, the participants suggested that the sampling strategies should be split between selective (with selecting criteria) and comprehensive (including as many objects as possible).

The dimension theoretical lens indicates whether a taxonomy uses a theoretical lens (yes) or not (no). Usually, researchers use these in morphological taxonomies to entangle empirical data with conceptual underpinnings. Exemplary frameworks are the VISOR-Framework (El Sawy \& Pereira, 2013) or the $V^{4}$-Framework (Al-Debei \& Avison, 2010).

\section{Meta-dimension: development}

In terms of the development method, taxonomies in IS often rely on Nickerson et al. (2013), a fact that is also illustrated by Szopinski et al. (2019b). In terms of business model taxonomies, $84 \%$ of the articles use the method of Nickerson et al. (2013), followed by numerical (6\%), grounded theory (3\%), multidimensional scaling (3\%), and ad hoc (i.e., not unambiguously identifiable) methods (3\%).

The dimensions for industry and technology scope emphasize whether the business model taxonomies either focus on a specific industry or technology or are rather generic (see Table 5 for details).

Depth of analysis describes whether the business model taxonomy aims to produce conceptually narrow or wide characteristics. For example, in Remane et al. (2016)'s taxonomy of car-sharing business models, they provide intense details, such as explaining how keys are exchanged for vehicle access. Contrarily, other business model taxonomies, e.g., Möller et al. (2019), provide general characteristics, such as what platform type a business model employs. Both have merit in their own right, and one could argue that both the design of specific and general taxonomies is needed to grasp a field of study fully. That notion is supported by Glass and Vessey (1995, p. 65), who state that in taxonomy design, "(...) you must choose between a very specific classification that serves a particular purpose and a more general classification that serves many purposes." Conceptually, one could link general and specific taxonomies to respective business model frameworks, e.g., investigating a general concept such as digital business models (Möller et al., 2019) and, correspondingly, a respective sub-type, such as data-driven business models (Möller et al., 2020).

\section{Meta-dimension: representation}

Concerning exclusivity, taxonomies should have mutually exclusive characteristics (Nickerson et al., 2013). However, we observe that taxonomies either adhere to or do not adhere to mutually exclusive characteristics. Some authors indicate which dimensions have mutually exclusive characteristics and which do not. For example, Paukstadt et al., (2019a, pp. 8-9) refer to the dimensions of customer segments and monetary value and explain that mutually exclusive characteristics would not "(...) reflect the complexity of all identified BMs and the subsequent information loss would have 
Table 5 Business model taxonomy coverage based on our sample

\begin{tabular}{|c|c|c|c|c|c|c|}
\hline Industry & Generic & $\begin{array}{c}\text { Industry } \\
4.0\end{array}$ & $\begin{array}{l}\text { Block- } \\
\text { chain }\end{array}$ & $\begin{array}{l}\text { Digital } \\
\text { Platforms }\end{array}$ & IoT & $\begin{array}{l}\text { Genetic } \\
\text { Testing }\end{array}$ \\
\hline Generic & $\begin{array}{l}\text { (Bock and Wiener } \\
\text { 2017; Engelbrecht et } \\
\text { al. 2016; Ertz et al. } \\
\text { 2019; Hartmann et } \\
\text { al. 2016; Remane et } \\
\text { al. 2017b; Weking et } \\
\quad \text { al. 2018a) }\end{array}$ & $\begin{array}{l}\text { (Weking et } \\
\text { al. 2018b; } \\
\text { Weking et al. } \\
\text { 2020b) }\end{array}$ & $\begin{array}{l}\text { (Tönnissen } \\
\text { et al. 2020; } \\
\text { Weking et al. } \\
\text { 2020a) }\end{array}$ & $\begin{array}{l}\text { (Fruhwirth et } \\
\text { al. 2020; } \\
\text { Perscheid et } \\
\text { al. 2020; } \\
\text { Staub et al. } \\
2021 ; \\
\text { Täuscher and } \\
\text { Laudien } \\
2017 \text {; } \\
\text { Wulfert et al. } \\
2021 \text { ) } \\
\end{array}$ & $\begin{array}{l}\text { (Hodapp et } \\
\text { al. 2019) }\end{array}$ & \\
\hline$\overline{\text { Logistics }}$ & $\begin{array}{l}\text { (Möller et al. 2019; } \\
\text { Möller et al. 2020) }\end{array}$ & & & & \multirow{5}{*}{\multicolumn{2}{|c|}{ WHITE SPOTS }} \\
\hline Energy & $\begin{array}{c}\text { (Paukstadt et al. } \\
\text { 2019) }\end{array}$ & & & & & \\
\hline FinTech & $\begin{array}{c}\text { (Eickhoff et al. 2017; } \\
\text { Gimpel et al. 2018) }\end{array}$ & & $\begin{array}{c}\text { (Beinke et al. } \\
\text { 2018) }\end{array}$ & & & \\
\hline Mobility & $\begin{array}{c}\text { (Lembcke et al. } \\
\text { 2020; Remane et al. } \\
\text { 2016; Remane et al. } \\
\text { 2017a) }\end{array}$ & & & & & \\
\hline Music & $\begin{array}{c}\text { (Katsma and Spil } \\
2010) \\
\end{array}$ & & & & & \\
\hline Healthcare & & & & & & $\begin{array}{l}\text { (Thiebes et } \\
\text { al. 2020) }\end{array}$ \\
\hline Smart City & & & $\begin{array}{l}\text { (Nagel et al. } \\
\text { 2019; Nagel } \\
\text { and Kranz } \\
2020)\end{array}$ & & & \\
\hline Manufacturing & (Azkan et al. 2020) & & & & $\begin{array}{l}\text { (Passlick et } \\
\text { al. 2020) }\end{array}$ & \\
\hline
\end{tabular}

threatened the taxonomy's purpose". Thus, the dimension specifies three choices for exclusivity, namely mutual, partial, or none.

In terms of visualization, our taxonomy reflects common findings that authors vary in how they visualize their results to best possibly fulfill a particular task (Szopinski et al., 2020). The most common visual representation is the morphological field with $71 \%$ in our data set and an absolute number of 22 of 31 business model taxonomies (see Table 3), followed by tables/matrices (16\%) and hierarchies (13\%).

\section{Meta-dimension: analysis}

Further application refers to the taxonomy, either being the paper's final product or the basis for additional steps. Our findings suggest that, mainly, authors generate clusters based on the taxonomy and, subsequently, (arche-)types from the clusters. Thereby, two clustering tools are applied in our sample, the statistical programming language $R$ that includes different functions for statistical analysis (e.g., the package cluster (Maechler et al., 2019)) and the software SPSS. The most popular clustering algorithm in our sample is agglomerative hierarchical clustering (usually based on Ward (1963)). Following Punj and Stewart (1983)'s recommendations, some papers apply two clustering algorithms to compare the results to enhance the validity of the clustering. In that case, the authors use agglomerative hierarchical clustering and K-means. Other, more singularly used algorithms are k-medoïds and multiscale bootstrap resampling or qualitative clustering. 


\section{Discussion and lessons learned}

\section{Synthesizing the status quo of business model taxonomies}

Regarding the diffusion of business model taxonomies (RQ1), we could identify focal industries, technologies, and combinations of research opportunities. We juxtapose the business model taxonomies' industries and technologies to visualize their coverage, intersection points, and white spots (i.e., no taxonomy exists that opens future research avenues). Moreover, it is observable that business model taxonomies usually focus either on an industry or a technology and rarely consider both (see Table 5).

Business model taxonomies store empirical knowledge for reuse (Lüdeke-Freund et al., 2018; Rich, 1992). While we cannot make a general statement about which business model taxonomy is more beneficial, we recommend focusing on the white spots disclosed by the status quo analysis. Although these white spots provide promising impulses for future avenues, they only give first indications for this. Some combinations of industries and technologies might be more valuable to explore than others. For example, by not aiming to exclude opportunities prematurely, we would expect more business model opportunities for (specific) industry 4.0-technologies in (specific) applications of healthcare than in the music domain. As another example, in contrast to the specific applicability, technologies such as 'digital platform' seem applicable to almost any industry (Reuver et al., 2018). They, therefore, provide possibilities for adaption across domain-specific boundaries. Subsequently, evaluation and ranking of the validity and the potential benefits of each white spot are required. Moreover, the white spots represent a snapshot of our sample, which can be extended over time through additional taxonomies.

Based on that overview, we analyzed how the configurations (i.e., specific or generic) are distributed across our sample. We contrasted technology with industry foci and calculated the percent distribution across the sample to make

Table 6 Numerical juxtaposition of industries and technologies

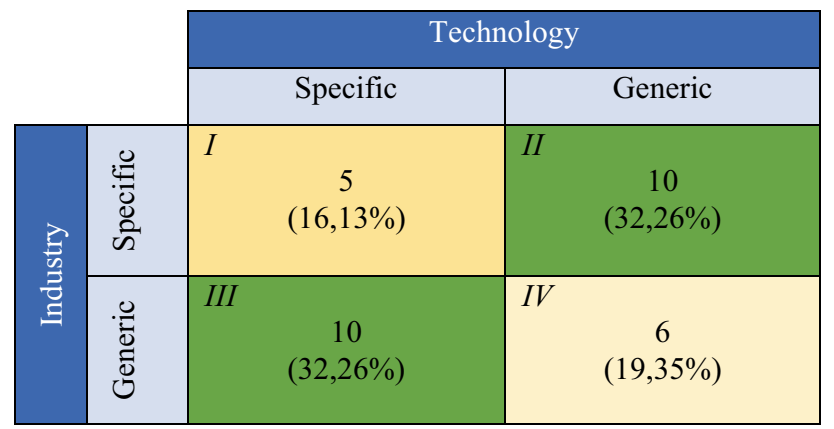

the business model taxonomy coverage more transparent. That analysis results in a $2 \times 2$ matrix with four quadrants (see Table 6), which we explain here as follows:

- Quadrant I hosts taxonomies specific to industry and technology. Examples are Beinke et al. (2018)'s taxonomy of FinTech start-ups using blockchain or Passlick et al. (2021)'s taxonomy of business models for predictive maintenance (IoT application) in manufacturing industries. The potential of business model taxonomies in this quadrant lies in explicating business model potentials in specific industries with dedicated technologies. Hence, this cluster acts as a cumulative storage that generates more in-depth knowledge for a specific industry or/and technology. Contrary to taxonomies in other quadrants, these business model taxonomies are highly focused and conceptually narrow.

- Quadrant II contains taxonomies that analyze a specific industry but are generic in terms of technology. For instance, Remane et al. (2016) and Lembcke et al. (2020) propose industry-specific taxonomies for car- and ridesharing. In this quadrant, the potential lies in cumulating generic business model research for specific industries independent from technologies. Researchers and practitioners can draw on rich business model knowledge of an industry and contextualize it with any technology.

- Quadrant III includes taxonomies specific to technology. For example, taxonomies that are tailored for blockchain business models (e.g., Weking et al. (2020a)) or data marketplace business models (e.g., Fruhwirth et al. (2020)) without referring to a particular industry. This quadrant accumulates empirical business model knowledge for technologies, which can be reused and adapted to specific industries.

- Quadrant IV consists of taxonomies that neither focus on a specific industry nor a technology. These taxonomies generate generic knowledge for business models, for example, in developing general types of data-driven business models or patterns (Hartmann et al., 2016; Weking et al., 2018a). In this quadrant, the potential lies in generating general insights about business models that can further develop the core concept without being too narrow in terms of industry or technology.

Overall, gaining more coverage would contribute to the knowledge base on business models - particularly to descriptive design knowledge (e.g., what dimensions can be considered when designing a business model). This knowledge serves as an input for further developments, including transforming descriptive into prescriptive statements for design and action (Gregor \& Hevner, 2013) through conceptual grounding (Goldkuhl, 2004) as well as generalizing from empirical to theoretical statements (Lee \& Baskerville, 
2012) or deriving additional types of theory that demand the basic form of a theory (e.g., taxonomy) as a necessary foundation (Gregor, 2006). As 90\% of business models recombine existing patterns, it seems reasonable to identify characteristics for various technologies and industries (Gassmann et al., 2016, 2017).

Furthermore, we can observe commonalities across taxonomies that focus on similar industries or technologies. For example, taxonomies in our sample dealing with the blockchain technology indicate whether the blockchain is public or private or what type of protocol (e.g., Ethereum or Bitcoin) is used (Nagel \& Kranz, 2020; Nagel et al., 2019; Weking et al., 2020a). They are typically visualized as morphology, draw on selective sampling, and apply a theoretical lens in terms of design. The taxonomies on blockchain differ in their conceptual depth (from narrow to wide), data collection strategies, and object of analysis (start-ups vs. incumbent firms), as well as their availability for generic and industry-specific purposes. As another example, taxonomies on digital platforms are mostly generic and not designed for specific industries. They have diverse strategies for data collection and objects of analysis and share similarities concerning the usage of a theoretical lens and the non-existence of clusters. However, while the taxonomies for an industry or technology hold some dimensions, they differ in how they are embedded; to provide more specific guidance on their design, there needs to be a higher diffusion.

Explicitly considering business model taxonomies for technologies is paramount, as the value of technology is dormant until "it is commercialized in some way in some way via a business model." (Chesbrough, 2010, p. 355). Filling the white spots would enrich the empirical body of knowledge about business models with new domains, which is a central goal of business model research (Lambert, 2015). For example, crossing the two design variables, technology-and industry-specific, allow for intuitive visualization of research opportunities on business model taxonomies. Thus, one can easily distinguish generic taxonomies addressing general business model elements (e.g., data-driven businesses (Hartmann et al., 2016)) and those focusing on industries, technologies, or combinations. Most address technologies and their utilization in business models, like blockchain or digital platforms. In contrast, others focus on specific industry sectors but do not refer to any particular technology.

\section{Guiding the design of business model taxonomies}

Also, options for designing business model taxonomies are derived (RQ2) that we have conceptually entangled with the underlying literature corpus and grounded through empirically analyzing published business model taxonomies. Next, we reflect on what we have learned from our study, seeking to present best practices and in-depth analysis of business model taxonomy design. One objective is to extend the descriptive character through rationales, argumentation, and recommendations in designing an artifact of the class business model taxonomy. By extending the boundaries of description to prescription, we address recent propositions of transforming the descriptive character of taxonomies in IS literature to a prescriptive one (Möller et al., 2021). Following Gregor (2009 p. 7), the underlying mechanism to formulate recommendations is "reflecting upon what has been done". Therefore, we went through each design dimension and formulated learnings that we have gathered from an in-depth study of the taxonomies. We did not consider all dimensions for these recommendations as some are naturally more critical (e.g., the data collection). In contrast, others are much more prone to be a result of personal preferences or the availability of tools (e.g., clustering tools).

Firstly, two significant lessons learned about the methodological nature of building taxonomies are formulated:

- Visualize according to your purpose: Taxonomies differ in how they are visualized (Szopinski et al., 2020). Our study produced three dominant visualizations that are common in business model research. The study did not investigate which visualization authors use to follow a specific goal. Yet, we see a general difference in using hierarchies and morphological fields or tables/matrices. From what we can gather, hierarchies are more natural to assign individual objects to a cluster. Contrarily, morphologies have the purpose of being used to find new configurations of an artifact. Thus, we recommend that authors of business model taxonomies provide argumentative reasoning for choosing a design option.

- Indicate situational exclusivity of dimensions: The literature on taxonomies, in general, clearly prescribes that characteristics should or even need to be mutually exclusive (e.g., Nickerson et al., (2013, p. 342)). Contrarily, Bailey (1994), Marradi (1990), Glass and Vessey (1995), and Fiedler et al. (1996) refer to mutually exclusiveness regarding the categorization of an object into a class rather than relating to individual characteristics of a dimension. We recommend that business model taxonomy designers should decide on complete, partial, or non-mutual exclusiveness and provide argumentative reasoning for their decision. If mutually exclusiveness is not maintained, authors usually point out that it would not adequately consider the complexity of business models. For example, business model taxonomies contain a dimension for specific revenue models, which, if mutually exclusive, rarely depict reality. Additionally, indicating exclusivity makes it easier for readers to understand it swiftly. 
Secondly, we formulate three main lessons learned for the actual content of a business model taxonomy:

\section{- Draw on start-ups as a rich source of information on} digital business models: A significant number of business model taxonomies analyze start-ups (45\%), which has pros and cons. Compared to incumbents with collections of business models (Sabatier et al., 2010), startups often employ only one or a few business model(s), reducing the complexity of identifying characteristics. Also, due to the innovative (and often digital) nature of start-ups, they provide rich sources of novel business ideas (Criscuolo et al., 2012; Engelbrecht et al., 2016). The novelty can be attributed to the fact that they follow green-field approaches, which are not burdened by preexisting infrastructure like most incumbent companies (Criscuolo et al., 2012; Hartmann et al., 2016). Contrarily, using start-ups as objects can have shortcomings as they employ high-risk and dynamic strategies, for which reason they might fail early or change their business models frequently (Cantamessa et al., 2018; Hartmann et al., 2016). However, we argue that using start-ups is beneficial regarding content (i.e., novel and digital business models) and the design method (i.e., availability and narrowness of data). Yet, one must consider that incumbent firms often have stood the test of time. Focusing solely on start-ups can bias one's view towards digital business models that can fail rapidly (e.g., because business models of start-ups are usually not proven to be successful). Designers should consider this trade-off when using start-up data or incumbent data.

- Employ the entire spectrum of conceptual depth: Arguably, to fully understand a domain of interest, one must leverage the full spectrum of conceptual depth. Thus, both types of taxonomies, i.e., those covering a large variety of business models and those covering only a very narrow range, have individual purposes and work conjointly. A taxonomy with a conceptual frame should subsume various business models that differ in highly general characteristics. Contrarily, a narrow taxonomy should consider a small range of business models and have very detailed, almost atomic characteristics (Möller et al., 2020). In this vein, investigating a domain fully requires broad and narrow conceptual investigation. Each taxonomy would provide value on different levels of abstraction. High-level taxonomies structure a field, per se, and uncover larger scale business model opportunities. Supplementary, low-level taxonomies complement these opportunities with more detailed and more easily implementable design dimensions and characteristics.

- Consider the power of archetypes: Archetypes elevate the empirical analysis of business models to abstracted, generalized types that complement the knowledge base through imitable and differentiable patterns (Ritter \& Lettl, 2018; Zhang et al., 2019). They enable the differentiation between types of business models and allow for understanding, structuring, and innovation. The dominant mechanism to generate business model archetypes is applying cluster analysis. Thereby, the archetypes are centroids, i.e., the basic patterns at the core of a cluster, enabling differentiation from other archetypical patterns engraved in different clusters (Hunke et al., 2017; Wulf \& Blohm, 2020).

\section{Implications and limitations}

Overall, our work has several implications for theory and practice.

In business model research, the field of business model taxonomies is relatively young (see Fig. 1), though they are helpful and popularly published. As with every emerging artifact, there is a high variance in how to design them. We aim to contribute to the knowledge base of business model tooling and classification. By illustrating design options, researchers striving to design taxonomies can use our findings to explain their design rationales. Subsequently, our work has intersections with developing business models through canvasses or tools in general (Bouwman et al., 2012). The presented design options can also be used as a basis for creating new tooling, for instance, by prescribing the definition of specific foci in terms of a technology or industry (Bouwman et al., 2020). Accordingly, our metataxonomy supports the formalization of constructing new business models on a meta-level (Alt, 2020). Also, our work supports the accumulation of business models knowledge and their storage in taxonomies, advancing the available knowledge base in this field (Jacob, 2004; Lüdeke-Freund et al., 2018; Muntermann et al., 2015). Beyond illustrating the current state of taxonomies, several white spots and research gaps are highlighted that potentially have implications for further knowledge accumulation, and we extended the knowledge base through potential papers.

Relating to taxonomy research, we have identified several dimensions that stress the potential need for domainspecific taxonomy design. The contribution is similar to adjacent studies proposing novel ways to build taxonomies for a specific purpose - context-specific artifacts, for example, the requirements-driven taxonomy design of Notheisen et al. (2019) or the taxonomy design method of Sarkintudu et al. (2018). Design decisions, like focusing on a broad or narrow level of conceptual analysis, should be explained in any taxonomy. Whereas some dimensions consist of generally applicable design variables that should be transferable 
to additional domains, other dimensions might require to be adapted domain-specifically.

In terms of practice, our results act as a road map for practitioners, divided into three implications. Firstly, our work gives a generic overview of knowledge about business models for particular industries and technologies. Subsequently, practitioners might use our findings to draw from that rich body of knowledge. It gives them easy access to identify relevant business model taxonomies, which they can use to compare or innovate their own business, as well as helps to select a suitable type of taxonomy (e.g., industry-specific) for a practical problem. Secondly, practitioners can use our research to trigger research in their fields, such as forming research consortia with universities, applied research, or other institutions (Österle \& Otto, 2010). Particularly in interdisciplinary projects and networks, taxonomies are applied to provide impulses for new spin-offs, to create a (terminological) basis allowing to talk about the same thing, as well as present a snapshot that synchronizes the understanding from practice and research (e.g., Kammler et al. (2020)). Lastly, suppose business model taxonomies are not available in a domain or the required degree of conceptual depth. In that case, one can still draw from business model taxonomies of other fields to inspire potential innovation. For example, business model taxonomies outlining data utilization in logistics or manufacturing industries might pose starting points and learning effects for innovation in domains that are not yet covered (e.g., pharma).

Our study is subject to typical limitations. Concerning building our taxonomy on design options, other dimensions and characteristics might be considered more critical and described at a different level of detail and abstraction. Against this, we performed ex-post evaluation episodes to validate the artifact's usefulness. Moreover, it is a snapshot fixed in time, and new business model taxonomies might have been published since our research has ended. With any literature review, there is also a chance to miss papers. As the papers varied in their detail of transparency, we needed judgment for some characteristics or left them blank in some cases.

\section{Outlook}

Empirical classifications capture attributes of real firms that support understanding how firms do business, comparing new/available solutions, getting inspiration through configurable characteristics, and identifying archetypes (Massa et al., 2017). To promote this valuable stream of research, our article presents an overview of the current diffusion of business model taxonomies and methodological guidance on how to design such taxonomies. With this, we provide fertile soil for further research. Firstly, we encourage researchers to fill the outlined white spots (Table 5); a promising avenue covers more technologies and industries (Table 6). Extending the status quo with new technologies (e.g., artificial intelligence) or other industries (e.g., manufacturing and retail) would significantly contribute to the knowledge of business models. Moreover, crosschecking business model taxonomies with industries and technologies will help in uncovering peculiarities. Future research might integrate other analysis parameters since we have examined our sample along the two dimensions for technologies and industries (e.g., specific mechanisms (Vorbohle et al., 2021)). Secondly, since we found that archetypes have great potential to contribute to business model design, further investigation on the interplay between both artifacts, the taxonomy itself, and archetypes that are based on the taxonomy is needed (e.g., in which settings designers are more likely to use which artifact). Thirdly, in case of maturity and availability of taxonomies, researchers are enabled to examine similarities and differences within a particular industry or technology (e.g., mainly rely on start-up data) as well as derive different 'design types' of business model taxonomies (e.g., 'meta taxonomies' that consolidate available taxonomies; e.g., Dehnert et al. (2021)). Fourthly, as a complement to empirical taxonomies, future research can investigate the coverage and intended purpose of other classification types, such as typologies ${ }^{5}$ containing theoretical and/or conceptual knowledge. Thereby, research could explore in which situation a specific classification type is best suitable and provide design variables for such classifications in general, which would have broader implications. Also, the underlying empirical database could be extended with taxonomies that originate in practice (e.g., to include expert-driven business model classifications), which could help triangulate our findings. The design options for business model taxonomies can act as the basis to identify evolution potential in business model taxonomies and compare their morphological configuration longitudinally at different points in time, which allows drawing conclusions about the (re-)use and evolution of business model taxonomies.

\footnotetext{
5 The authors acknowledge that typologies can be seen as a type of classification (e.g., Fiedler et al. (1996); Bailey (1994) and a form of theory (e.g., Doty and Glick (1994)).
} 


\section{Appendix 1: Sample of business model taxonomies}

Table 7 Sample of business model taxonomies

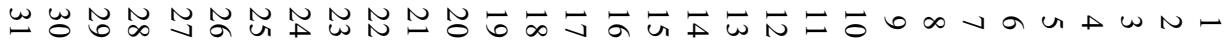

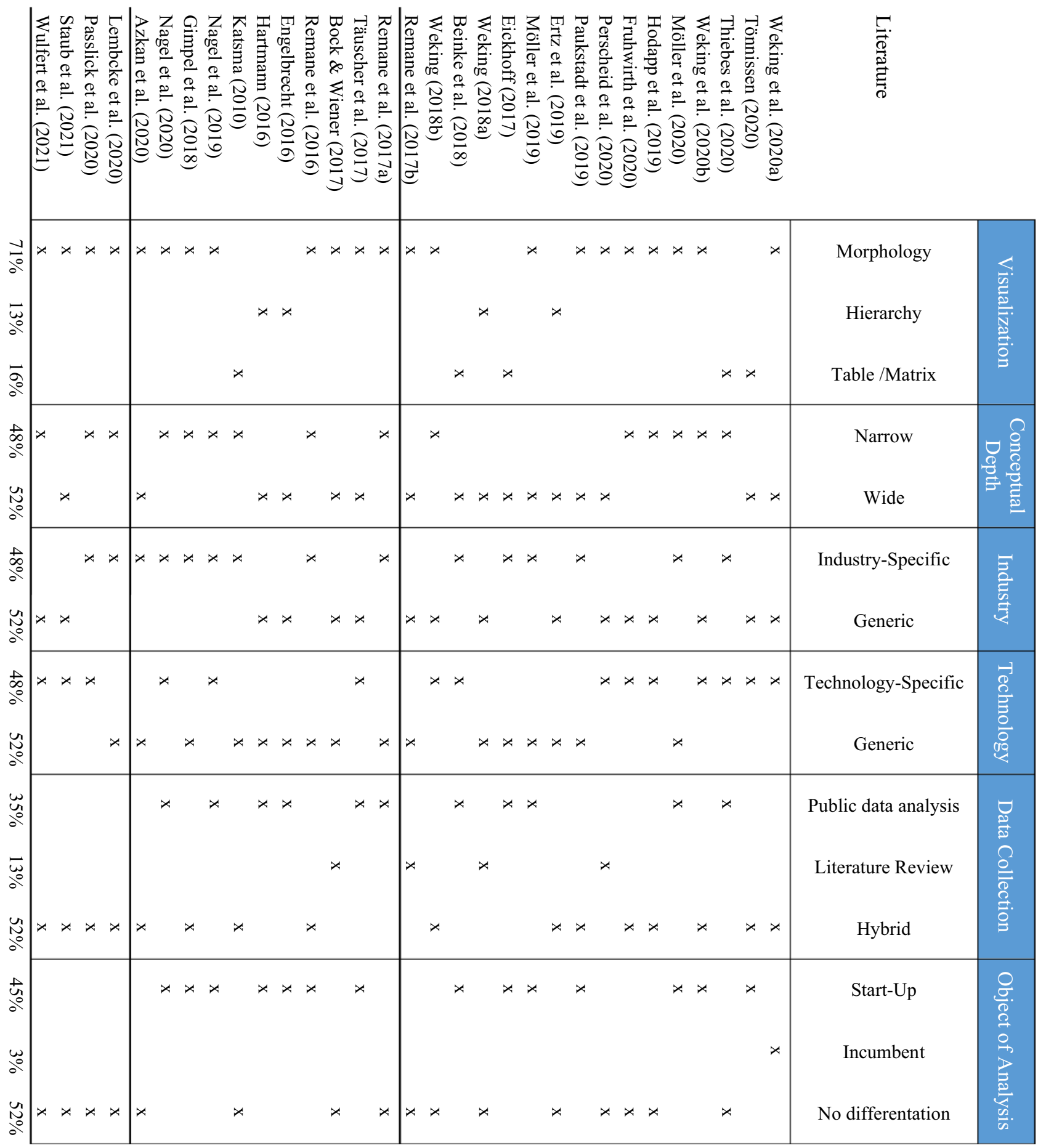


Table 7 (continued)

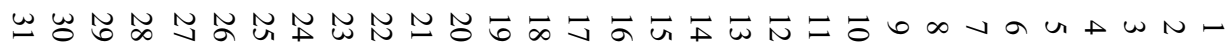

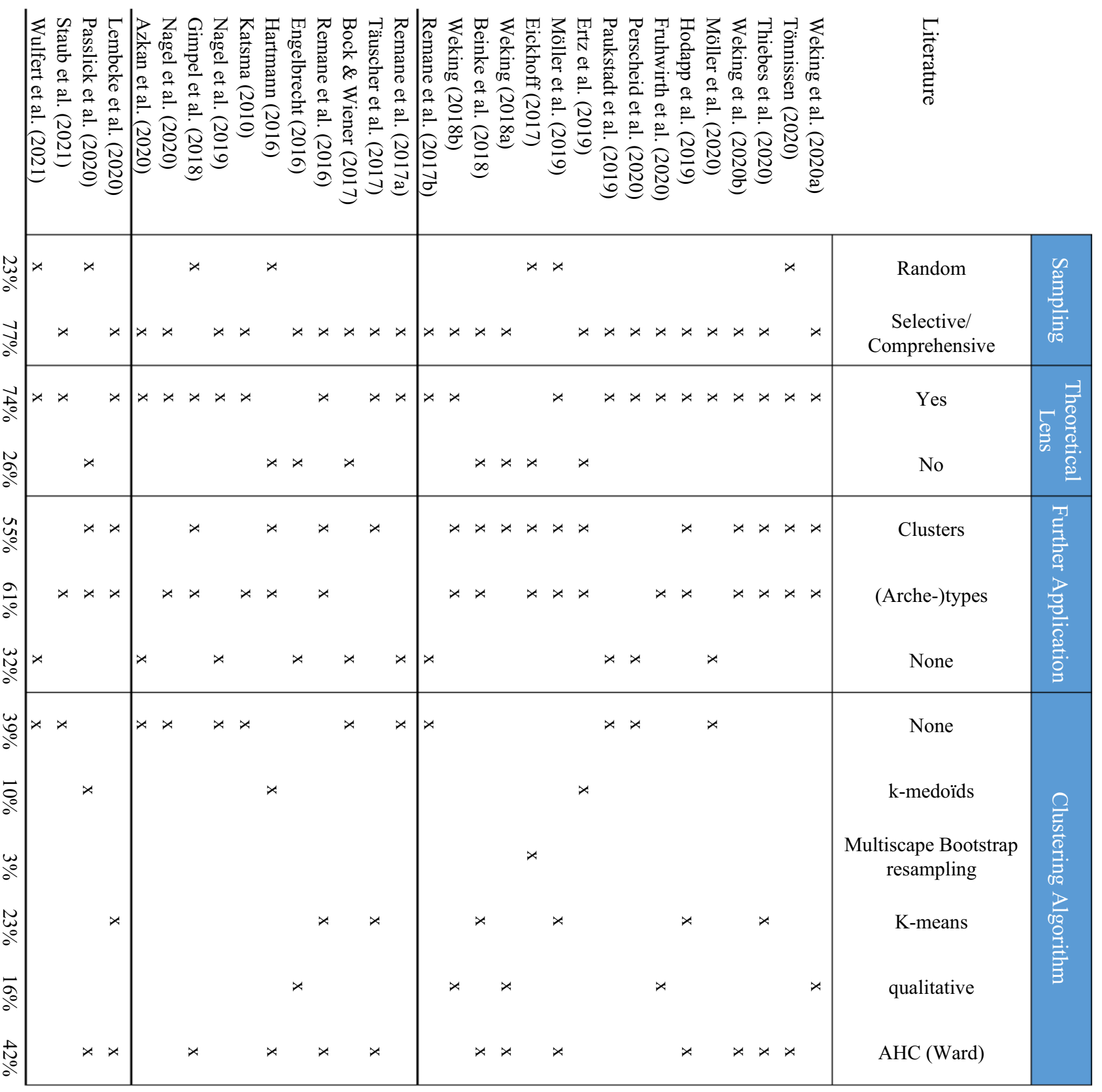


Table 7 (continued)

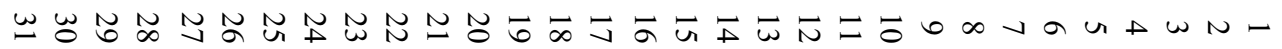

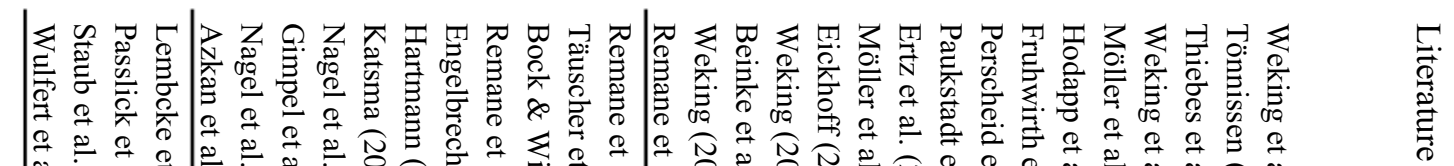

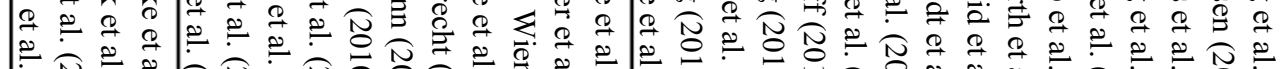

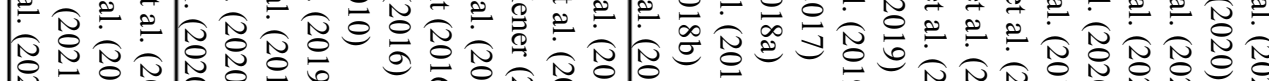

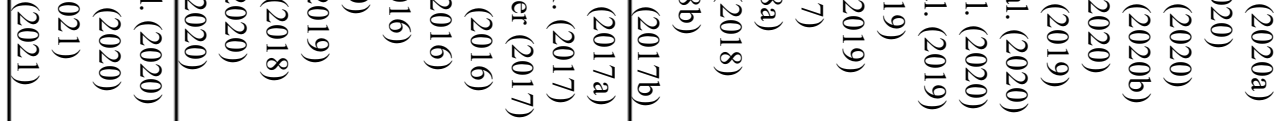

.

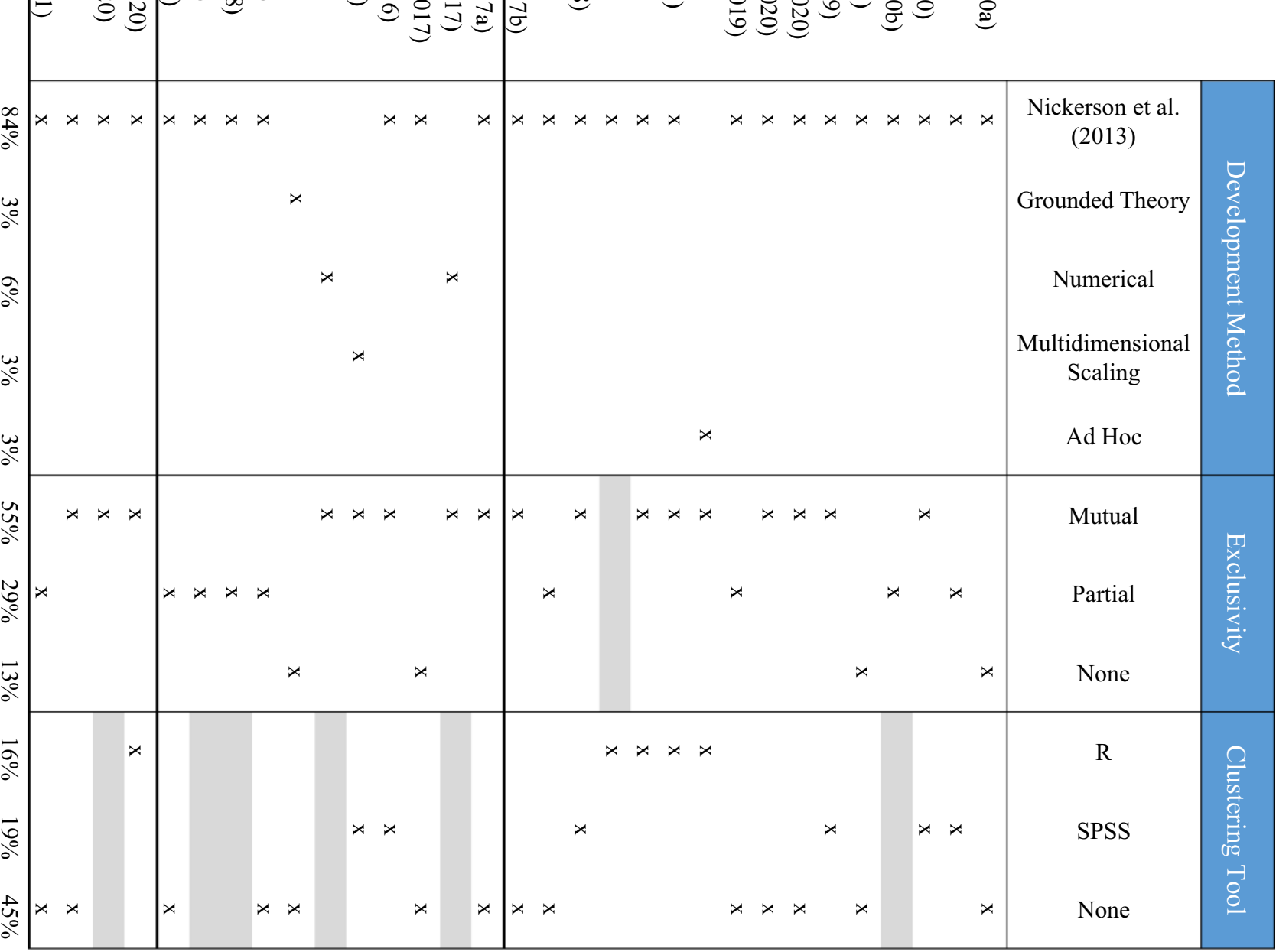




\section{Appendix 2: Definition of taxonomy \\ characteristics}

Table 8 summarizes the taxonomy's dimensions and characteristics.

Table 8 Definitions of characteristics

\begin{tabular}{|c|c|}
\hline Characteristic & Definition \\
\hline \multicolumn{2}{|c|}{ Dimension 1: Object of Analysis } \\
\hline Start-Up & The object of analysis is start-ups \\
\hline Incumbents & The object of analysis is incumbents \\
\hline No differentiation & The object of analysis does not differentiate between start-ups or incumbents \\
\hline \multicolumn{2}{|l|}{ Dimension 2: Data Collection } \\
\hline Public Data Analysis & The data are collected primarily through public data analysis \\
\hline Systematic Literature Review & The data are collected primarily through a systematic review of the literature \\
\hline Hybrid & The data are collected through mixing public data analysis, literature review, and other methods (e.g., interviews) \\
\hline \multicolumn{2}{|l|}{ Dimension 3: Data Sampling } \\
\hline Random & The data are sampled randomly \\
\hline Selective/Comprehensive & The data are sampled either through selection or comprehensively \\
\hline \multicolumn{2}{|l|}{ Dimension 4: Theoretical Lens } \\
\hline Yes & The business model taxonomy uses a theoretical lens (e.g., business model framework) to analyze the data \\
\hline No & $\begin{array}{l}\text { The business model taxonomy does not use a theoretical lens (e.g., business model framework) to analyze the } \\
\text { data }\end{array}$ \\
\hline \multicolumn{2}{|c|}{ Dimension 5: Development Method } \\
\hline (Nickerson et al., 2013) & The business model taxonomy is designed using the method of Nickerson et al. (2013) \\
\hline Numerical & The business model taxonomy is designed numerically through cluster analysis \\
\hline MDS & The business model taxonomy is designed using multidimensional scaling \\
\hline Grounded Theory & The business model taxonomy is designed using Grounded Theory \\
\hline Ad Hoc & The business model taxonomy is designed ad hoc or without a clearly identifiable method \\
\hline \multicolumn{2}{|l|}{ Dimension 6: Industry Scope } \\
\hline Industry-Specific & The business model taxonomy analyzes a business model in a specific industry \\
\hline Generic & The business model taxonomy analyzes business model taxonomies without a specific industry \\
\hline \multicolumn{2}{|l|}{ Dimension 7: Technology Scope } \\
\hline Technology-Specific & The business model taxonomy analyzes business models of a specific technology \\
\hline Generic & The business model taxonomy does not analyze the business model of a specific technology \\
\hline \multicolumn{2}{|l|}{ Dimension 8: Depth of Analysis } \\
\hline Narrow & The depth of analysis is narrow, i.e., the dimensions and characteristics are on a detailed level \\
\hline Wide & The depth of analysis is wide, i.e., the dimensions and characteristics are general and abstract \\
\hline \multicolumn{2}{|l|}{ Dimension 9: Exclusivity } \\
\hline Mutual & All characteristics in each dimension are mutually exclusive \\
\hline Partial & Some characteristics in some dimensions are mutually exclusive \\
\hline None & All characteristics in each dimension are not mutually exclusive \\
\hline \multicolumn{2}{|l|}{ Dimension 10: Visualization } \\
\hline Morphological Field & The business model taxonomy is visualized as a morphological field (e.g., see Table 3 ) \\
\hline Hierarchies & The business model taxonomy is organized in a hierarchy, usually visualized as a tree \\
\hline Tables/Matrices & The business model taxonomy is visualized as a table or matrix \\
\hline \multicolumn{2}{|c|}{ Dimension 11: Further Application } \\
\hline Clusters & The taxonomy is used to develop clusters of business models \\
\hline (Arche-)types & The taxonomy is used to develop archetypes of business models \\
\hline None & The taxonomy is the final product \\
\hline \multicolumn{2}{|l|}{ Dimension 12: Clustering Tool } \\
\hline $\mathrm{R}$ & Clusters are developed using the statistical programming language $\mathrm{R}$ \\
\hline SPSS & Clusters are developed using SPSS \\
\hline None & No clusters are developed \\
\hline
\end{tabular}


Table 8 (continued)

\begin{tabular}{ll}
\hline Characteristic & Definition \\
\hline Dimension 13: Clustering Algorithm & \\
Agglomerative Hierarchical Clustering (AHC) & The clusters are developed using AHC \\
K-Means & The clusters are developed using k-means \\
K-medoïds & The clusters are developed using K-medoïds \\
Multiscale Bootstrap Resampling & The clusters are developed using MBR \\
Qualitative & The clusters are developed qualitatively \\
None & No clusters are developed
\end{tabular}

\section{Appendix 3: Comparison of meta-dimensions}

Theoretical lenses are frequently used to guide business model design. Usually, authors used meta-dimensions in morphological taxonomies and structure dimensions and characteristics inside their conceptual borders. In that sense, they act as a theoretical lens through which the underlying literature-based or empirical data is seen (Niederman $\&$ March, 2019). Commonly, authors use business model ontologies from the literature, for example, the VISORFramework (El Sawy \& Pereira, 2013) or the $V^{4}$-Framework (Al-Debei \& Avison, 2010; Al-Debei et al., 2008).

Table 9 shows meta-dimensions from our dataset. We aggregated and synthesized each meta-dimension to a higher-order view to construct a holistic view of business models. We contribute to establishing a comprehensive view of business models and standardizing what meta-dimensions should guide business model taxonomy design. Subsequently, we recommend including five mandatory views: customer, value proposition, value chain, network, and finance. Depending on the technology or industry domain the business model taxonomy addresses, researchers can add specific views. Examples are the blockchain-specific meta-dimensions in Nagel et al. (2019), such as blockchain applications. 


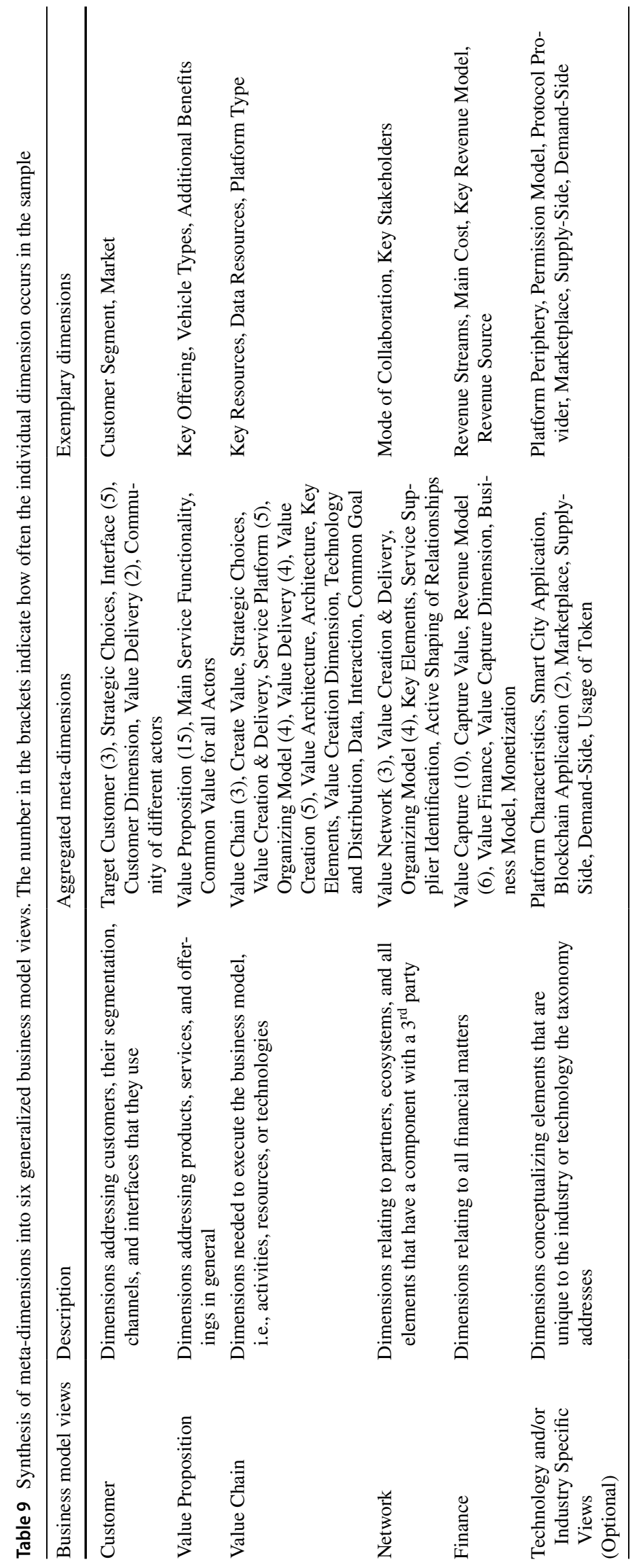




\section{Appendix 4: Details of the structured literature review}

In order to provide and synthesize the process of our systematic literature review, we draw on the template as proposed by Schoormann et al. (2021). This template conceptualizes the main components that should be considered during the specification of a search strategy and allows to visually processing the search's configuration (see Fig. 2).

Fig. 2 Exposition of the systematic literature review based on the template of Schoormann et al. (2021)

\begin{tabular}{|c|c|c|c|}
\hline \multicolumn{4}{|c|}{$\begin{array}{l}\text { Purpose of Search Detailed analysis of business model taxonomies for the } \\
\text { purpose of deriving design options to increase rigor in their design }\end{array}$} \\
\hline \multicolumn{4}{|c|}{$\begin{array}{l}\text { Related Disciplines and Research Streams } \\
\text { Taxonomy Design, Business Model Research, Business Model Taxonomy }\end{array}$} \\
\hline \multicolumn{4}{|c|}{$\begin{array}{l}\text { Seminal Work } \\
\text { E.g., Nickerson et al. (2013), Lambert (2015), Glass \& Vessey (1995)... }\end{array}$} \\
\hline $\begin{array}{l}\text { Search Item } \\
\text { Collection } \\
\text {,Business model', } \\
\text { 'Taxonomy', } \\
\text {,Classification' }\end{array}$ & $\begin{array}{l}\text { Search } \\
\text { Sources } \\
\text { Studies that develop } \\
\text { business model } \\
\text { taxonomies based on } \\
\text { AISeL, Scopus, and } \\
\text { Google Scholar } \\
\text { databases. }\end{array}$ & $\begin{array}{l}\text { Preliminary } \\
\text { Combinations }\end{array}$ & $\begin{array}{l}\text { Final } \\
\text { Search Phrase } \\
\text {,Business model', } \\
\text { 'Taxonomy', } \\
\text {,Classification' }\end{array}$ \\
\hline \multicolumn{4}{|c|}{$\begin{array}{l}\text { Inclusion and Exclusion Criteria } \\
\text { Taxonomy Design, Business Model Research, Business Model Taxonomy }\end{array}$} \\
\hline $\begin{array}{l}\text { Collaboration } \\
\text { Author Team }\end{array}$ & & & \\
\hline
\end{tabular}

\section{Appendix 5: Taxonomy development iterations}

In the $1^{\text {st }}$ iteration, we deduced dimensions for visualization, depth of analysis, industry scope, and development method and formalize the taxonomy as follows:

$$
\mathrm{T}_{1 \mathrm{st} \text { iteration }}=\{
$$

$\mathrm{D}_{1}$ (Visualization) I $\mathrm{C}_{1}$ (Morphological field, Hierarchy, Mathematical Set, Visual, Table/Matrix, Textual \}, $\mathrm{D}_{2}$ (Depth of Analysis) $\mid \mathrm{C}_{2}$ (Narrow, Wide),

$\mathrm{D}_{3}$ (Industry Scope) $\mid \mathrm{C}_{3}$ (Industry-Specific, Generic), $\mathrm{D}_{4}$ (Development Method) $\mid \mathrm{C}_{4}$ ((Nickerson et al. 2013))\}

In the $2^{\text {nd }}$ iteration, the taxonomy has been updated is as follows:
$\mathrm{T}_{2 \text { nd iteration }}=\{$

$\mathrm{D}_{1}$ (Visualization) I $\mathrm{C}_{1}$ (Morphological field, Hierarchy, Mathematical Set, Visual, Matrix/Table, Textual) $\mathrm{D}_{2}$ (Exclusivity) $\mid \mathrm{C}_{2}$ (Mutual, Partial, None)

$\mathrm{D}_{3}$ (Depth of Analysis) I $\mathrm{C}_{3}$ (Narrow, Wide)

$\mathrm{D}_{4}$ (Industry Scope) $\mid \mathrm{C}_{4}$ (Industry-Specific, Generic)

$\mathrm{D}_{5}$ (Technology Scope) $\mid \mathrm{C}_{5}$ (Technology-Specific, Generic)

$\mathrm{D}_{6}$ (Meta-Dimensions) $\mid \mathrm{C}_{6}$ (Yes, No)

$\mathrm{D}_{7}$ (Development Method) $\mid \mathrm{C}_{7}$ (Nickerson et al. (2013), Numerical, MDS, Grounded Theory, Ad Hoc) $\mathrm{D}_{8}$ (Data Collection) $/ \mathrm{C}_{8}$ (Public Data Analysis, Literature Review, Hybrid)

$\mathrm{D}_{9}$ (Data Sampling) I $\mathrm{C}_{9}$ (Random, Selective/Comprehensive)

$\mathrm{D}_{10}$ (Object of Analysis) I $\mathrm{C}_{10}$ (Start-Ups, Incumbents, No Differentiation) 
$\mathrm{D}_{11}$ (Further Application) I $\mathrm{C}_{11}$ (Clusters, (Arche-) types, None)

$\mathrm{D}_{12}$ (Clustering Tool) $\mid \mathrm{C}_{12}$ (R, SPSS, None)

$\mathrm{D}_{13}$ (Clustering Algorithm) I $\mathrm{C}_{13}$ (AHC, K-Means, k-medoïds, MRB, Qualitative, None)\}

In the $3^{\text {rd }}$ iteration, finally, we introduced the notion of exclusivity of characteristics, which we determined for every dimension through discussion amongst the authors. The final taxonomy is as follows:

$\mathrm{T}_{\text {Final }}=\{$

$\mathrm{MD}_{1}$ (Data) \{

$\mathrm{D}_{1}$ (Object of Analysis) I $\mathrm{C}_{1}$ (Start-Ups, Incumbents, No Differentiation) $\mid \mathrm{EX}=\{\mathrm{N}\}$

$\mathrm{D}_{2}$ (Data Collection) I $\mathrm{C}_{2}$ (Public Data Analysis, Literature Review, Hybrid) $\mid \mathrm{EX}=\{\mathrm{Y}\}$

$\mathrm{D}_{3}$ (Data Sampling) $\mid \mathrm{C}_{3}$ (Random, Selective/Comprehensive) $\mid \mathrm{EX}=\{\mathrm{Y}\}$

$\mathrm{D}_{4}$ (Theoretical Lens) $\mid \mathrm{C}_{4}$ (Yes, No) $\left.\mid \mathrm{EX}=\{\mathrm{Y}\}\right\}$,

$\mathrm{MD}_{2}$ (Development) \{

$\mathrm{D}_{5}$ (Development Method) I $\mathrm{C}_{5}$ ( Nickerson et al. (2013), Numerical, MDS, Grounded Theory, Ad Hoc) I $\mathrm{EX}=\{\mathrm{Y}\}\}$

$\mathrm{D}_{6}$ (Industry Scope) $\mid \mathrm{C}_{6}$ (Industry-Specific, Generic) I $\mathrm{EX}=\{\mathrm{Y}\}$

$\mathrm{D}_{7}$ (Technology Scope) I $\mathrm{C}_{7}$ (Technology-Specific, Generic) $\mid \mathrm{EX}=\{\mathrm{Y}\}$

$\mathrm{D}_{8}$ (Depth of Analysis) $\mid \mathrm{C}_{8}$ (Narrow, Wide) $\mid \mathrm{EX}=$ $\{\mathrm{Y}\}$,

$\mathrm{MD}_{3}$ (Representation) \{

$\mathrm{D}_{9}$ (Exclusivity) $\mid \mathrm{C}_{9}$ (Mutual, Partial, None) $\mid \mathrm{EX}=$ $\{\mathrm{Y}\}$

$\mathrm{D}_{10}$ (Visualization) $\mid \mathrm{C}_{10}$ (Morphological field, Hierarchy, Table/Matrix) $\mid \mathrm{EX}=\{\mathrm{Y}\}\}$,

$\mathrm{MD}_{4}$ (Analysis) \{

$\mathrm{D}_{11}$ (Further Application) I $\mathrm{C}_{11}$ (Clusters, (Arche-) types, None) $\mid \mathrm{EX}=\{\mathrm{N}\}$

$\mathrm{D}_{12}$ (Clustering Tool) $\mid \mathrm{C}_{12}$ (R, SPSS, None) $\mid \mathrm{EX}=$ $\{\mathrm{Y}\}$

$\mathrm{D}_{13}$ (Clustering Algorithm) I $\mathrm{C}_{13}$ (AHC, K-Means, k-medoïds, $\mathrm{MRB}$, Qualitative, None) $\mid \mathrm{EX}=\{\mathrm{Y}\}\}\}$
Open Access This article is licensed under a Creative Commons Attribution 4.0 International License, which permits use, sharing, adaptation, distribution and reproduction in any medium or format, as long as you give appropriate credit to the original author(s) and the source, provide a link to the Creative Commons licence, and indicate if changes were made. The images or other third party material in this article are included in the article's Creative Commons licence, unless indicated otherwise in a credit line to the material. If material is not included in the article's Creative Commons licence and your intended use is not permitted by statutory regulation or exceeds the permitted use, you will need to obtain permission directly from the copyright holder. To view a copy of this licence, visit http://creativecommons.org/licenses/by/4.0/.

\section{References}

Abdollahi, G., \& Leimstoll, U. (2011). A Classification for Business Model Types in E-commerce. Proceedings of the 17th Americas Conference on Information Systems, Detroit: USA.

Al-Debei, M. M., \& Avison, D. (2010). Developing a Unified Framework of the Business Model Concept. European Journal of Information Systems, 19(3), 359-376. https://doi.org/10.1057/ ejis. 2010.21

Al-Debei, M. M., El-Haddadeh, R., \& Avison, D. (2008). Defining the Business Model in the New World of Digital Business. Proceedings of the 14th Americas Conference on Information Systems, Toronto: Canada.

Alt, R. (2020). Electronic Markets on business model development. Electronic Markets, 30(3), 405-411. https://doi.org/10.1007/ s12525-020-00438-Z

Amit, R., \& Zott, C. (2001). Value Creation in e-Business. Strategic Management Journal, 22(6-7), 493-520. https://doi.org/10.1002/ smj.187

Asadullah, A., Faik, I., \& Kankanhalli, A. (2018). Digital Platforms: A Review and Future Directions. Proceedings of the 22nd Pacific Asia Conference on Information Systems, Yokohama: Japan.

Azkan, C., Iggena, L., Gür, I., Möller, F., \& Otto, B. (2020a). A Taxonomy for Data-Driven Services in Manufacturing Industries. Proceedings of the 24th Pacific Asia Conference on Information Systems, Dubai: UAE.

Azkan, C., Möller, F., Meisel, L., \& Otto, B. (2020b). A Service-Dominant Logic Perspective on Data Ecosystems: A Case-Study based Morphology. Proceedings of the 28th European Conference on Information Systems, An Online AIS Conference.

Baden-Fuller, C., \& Morgan, M. S. (2010). Business Models as Models. Long Range Planning, 43(2-3), 156-171. https://doi.org/10. 1016/j.lrp.2010.02.005

Bailey, K. D. (1994). Typologies and Taxonomies: An Introduction to Classification Techniques. Sage Publications.

Beinke, J., Teuteberg, F., \& Nguyen Ngoc, D. (2018). Towards a Business Model Taxonomy of Startups in the Finance Sector using Blockchain. Proceedings of the 39th International Conference on Information Systems, San Francisco: USA.

Berger, S., Denner, M.-S., \& Roeglinger, M. (2018). The Nature of Digital Technologies-Development of a Multi-layer Taxonomy. Proceedings of the 26th European Conference on Information Systems, Portsmouth: United Kingdom.

Bock, M., \& Wiener, M. (2017). Towards a Taxonomy of Digital Business Models - Conceptual Dimensions and Empirical Illustrations. Proceedings of the 38th International Conference on Information Systems, Seoul: South Korea.

Bouwman, H., de Reuver, M., Heikkilä, M., \& Fielt, E. (2020). Business model tooling: Where research and practice meet. Electronic Markets, 30(3), 413-419. https://doi.org/10.1007/ s12525-020-00424-5 
Bouwman, H., Reuver, M. de, Solaimani, S., Daas, D., Haaker, T., Janssen, W., Iske, P., \& Walenkamp, B. (2012). Business Models Tooling and a Research Agenda. Proceedings of the 25th Bled eConference, Bled: Slovenia.

Breitfuss, G., Fruhwirth, M., Pammer-Schindler, V., Stern, H., \& Dennerlein, S. M. (2019). The Data-Driven Business Value Matrix - A Classification Scheme for Data-Driven Business Models. Bled eConference.

Burkhart, T., Krumeich, J., Werth, D., \& Loos, P. (2011). Analyzing the Business Model Concept - A Comprehensive Classification of Literature. Proceedings of the 32nd International Conference on Information Systems, Shanghai: China.

Cantamessa, M., Gatteschi, V., Perboli, G., \& Rosano, M. (2018). Startups' roads to failure, Sustainability, 10(7), p. 2346 https://doi. org/10.3390/su10072346.

Casadesus-Masanell, R., \& Ricart, J. E. (2011). How to design a winning business model. Harvard Business Review, 89(1/2), 100-107.

Chesbrough, H. (2007). Business model innovation: It's not just about technology anymore. Strategy \& Leadership, 35(6), 12-17. https://doi.org/10.1108/10878570710833714

Chesbrough, H. (2010). Business Model Innovation: Opportunities and barriers. Long Range Planning, 43(2-3), 354-363. https://doi. org/10.1016/j.lrp.2009.07.010

Cooper, H. M. (1988). Organizing Knowledge Syntheses: A Taxonomy of Literature Reviews. Knowledge in Society, 1(1), 104-126. https://doi.org/10.1007/BF03177550

Criscuolo, P., Nicolaou, N., \& Salter, A. (2012). The elixir (or burden) of youth? Exploring differences in innovation between start-ups and established firms. Research Policy, 41(2), 319-333. https:// doi.org/10.1016/j.respol.2011.12.001

Cross, N. (1999). Design Research: A Disciplined Conversation. Design Issues, 15(2), 5-10. https://doi.org/10.2307/1511837

DaSilva, C., \& Trkman, P. (2014). Business Model: What It Is and What It Is Not. Long Range Planning, 47(6), 379-389. https:// doi.org/10.1016/j.lrp.2013.08.004

Dehnert, M., Gleiß, A., \& Reiss, F. (2021). What makes a data-driven business model? A consolidated taxonomy. Proceedings of the 29th European Conference on Information Systems, Marrakesh: Morocco.

Dos Santos, B., Fichman, R., \& Zheng, Z. (2014). Digital Innovation as a Fundamental and Powerful Concept in the Information Systems Curriculum. MIS Quarterly, 38(2), 329-353. https://doi.org/10. 25300/MISQ/2014/38.2.01

Doty, D. H., \& Glick, W. H. (1994). Typologies as a Unique Form of Theory Building: Toward Improved Understanding and Modeling. The Academy of Management Review, 19(2), 230-251. https://doi.org/10.5465/amr.1994.9410210748

Eickhoff, M., Muntermann, J., \& Weinrich, T. (2017). What do FinTechs actually do? A Taxonomy of FinTech Business Models. Proceedings of the 38th International Conference on Information Systems, Seoul: South Korea.

El Sawy, O. A., \& Pereira, F. (2013). Business Modelling in the Dynamic Digital Space an Ecosystem Approach. Springer.

Endres, H., Indulska, M., Ghosh, A., Baiyere, A., \& Broser, S. (2019). Industrial Internet of Things (IIoT) Business Model Classification. Proceedings of the 40th International Conference on Information Systems, Munich: Germany.

Engelbrecht, A., Gerlach, J., \& Widjaja, T. (2016). Understanding the Anatomy of Data-Driven Business Models - towards an Empirical Taxonomy. Proceedings of the 24th European Conference on Information Systems, Istanbul: Turkey.

Ertz, M., Leblanc-Proulx, S., Sarigollu, E., \& Morin, V. (2019). Made to break? A taxonomy of business models on product lifetime extension. Journal of Cleaner Production, 234, 867-880. https:// doi.org/10.1016/j.jclepro.2019.06.264
Fiedler, K. D., Grover, V., \& Teng, J. T. C. (1996). An Empirically Derived Taxonomy of Information Technology Structure and Its Relationship to Organizational Structure. Journal of Management Information Systems, 13(1), 9-34. https://doi.org/10.1080/ 07421222.1996 .11518110

Fielt, E. (2013). Conceptualising Business Models: Definitions, Frameworks and Classifications. Journal of Business Models, 1(1), 85-105. https://doi.org/10.5278/ojs.jbm.v1i1.706

Fruhwirth, M., Rachinger, M., \& Prlja, E. (2020). Discovering Business Models of Data Marketplaces. Proceedings of the 53rd Hawaii International Conference on System Sciences, Hawaii: USA.

Gambardella, A., \& McGahan, A. M. (2010). Business-Model Innovation: General Purpose Technologies and their Implications for Industry Structure. Long Range Planning, 43(2), 262-271. https://doi.org/10.1016/j.lrp.2009.07.009

Gassmann, O., Frankenberger, K., \& Csik, M. (2017). Geschäftsmodelle entwickeln: 55 innovative Konzepte mit dem St. Galler Business Model Navigator, Carl Hanser Verlag GmbH \& Company $\mathrm{KG}$.

Gassmann, O., Frankenberger, K., \& Sauer, R. (2016). Leading Business Model Research: The Seven Schools of Thought. In O. Gassmann, K. Frankenberger, \& R. Sauer (Eds.), Exploring the Field of Business Model Innovation: New Theoretical Perspectives (pp. 7-46). Springer International Publishing.

Giessmann, A., \& Legner, C. (2016). Designing business models for cloud platforms. Information Systems Journal, 26(5), 551-579. https://doi.org/10.1111/isj.12107

Gimpel, H., Rau, D., \& Röglinger, M. (2018). Understanding FinTech start-ups - a taxonomy of consumer-oriented service offerings. Electronic Markets, 28(3), 245-264. https://doi.org/10.1007/ s12525-017-0275-0

Glass, R. L., \& Vessey, I. (1995). Contemporary Application-Domain Taxonomies. IEEE Software, 12(4), 63-76. https://doi.org/10. $1109 / 52.391837$

Goldkuhl, G. (2004). Design Theories in Information Systems-a Need for Multi-Grounding. JITTA: Journal of Information Technology Theory and Application, 6(2), pp. 59-72.

Gregor, S. (2006). The Nature of Theory in Information Systems. MIS Quarterly: Management Information Systems, 30(3), 611-642. https://doi.org/10.2307/25148742

Gregor, S. (2009). Building Theory in the Sciences of the Artificial. Proceedings of the 4th International Conference on Design Science Research in Information Systems and Technology, Malvern: USA, New York, NY, USA: ACM, 4:1-4:10.

Gregor, S., \& Hevner, A. R. (2013). Positioning and Presenting Design Science Research for Maximum Impact. MIS Quarterly: Management Information Systems, 37(2), 337-355. https://doi.org/ 10.25300/MISQ/2013/37.2.01

Gordijn, J., Akkermans, H., \& van Vliet, H. (2000). Business modelling is not process modelling. In Springer (Ed.), Proceedings of the International Conference on Conceptual Modeling . Salt Lake City: USA.

Groth, P., \& Nielsen, C. (2015). Constructing a Business Model Taxonomy: Using statistical tools to generate a valid and reliable business model taxonomy. Journal of Business Models, 3(1), 4-21. https://doi.org/10.5278/ojs.jbm.v3i1.1211

Hanelt, A., Hildebrandt, B., \& Polier, J. (2015). Uncovering the Role of IS in Business Model Innovation - A Taxonomy-Driven Approach to Structure the Field. Proceedings of the 23rd European Conference on Information Systems, Münster: Germany.

Hartmann, P. M., Zaki, M., Feldmann, N., \& Neely, A. (2016). Capturing Value from Big Data - A Taxonomy of Data-Driven Business Models Used by Start-Up Firms. International Journal of Operations \& Production Management, 36(10), 1382-1406. https://doi. org/10.1108/IJOPM-02-2014-0098 
Hodapp, D., Remane, G., Hanelt, A., \& Kolbe, L. (2019). Business Models for Internet of Things Platforms: Empirical Development of a Taxonomy and Archetypes. Proceedings of the 14th International Conference on Wirtschaftsinformatik, Siegen: Germany, pp. $1768-1783$.

Hunke, F., Schüritz, R., \& Kuehl, N. (2017). Towards a Unified Approach to Identify Business Model Patterns: A Case of E-Mobility Services. In S. Za, M. Dragoicea, \& M. Cavallari (Eds.), Exploring Services Science (pp. 182-196). Springer International Publishing.

Jacob, E. (2004). Classification and Categorization: A Difference that Makes a Difference. Library Trends, 52(3), 515-540.

Johnson, P. A. (1994). The Theory of Architecture: Concepts Themes \& Practices. Wiley.

Kammler, F., Schoormann, T., Fuchs, A., Mauruschat, A., Thomas, O., \& Knackstedt, R. (2020). Innovationsnetzwerke als Treiber für Wissenschaft-Praxis-Kooperationen: Ein Erfahrungsbericht. HMD Praxis der Wirtschaftsinformatik, pp. 1-13.

Kamoun, F. (2008). Rethinking the business model with RFID. Communications of the Association for Information Systems, 22(35), 635-658. https://doi.org/10.17705/1CAIS.02235

Kamprath, M., \& Halecker, B. (2012). A Systematic Approach for Business Model Taxonomy-How to operationalize and compare large Quantities of Business Models? ISPIM Innovation Symposium, Seoul: South Korea.

Katsma, C., \& Spil, T. (2010). A taxonomy of digital music services. Proceedings of the 16th Americas Conference in Information Systems, Lima: Peru.

Labes, S., Hanner, N., \& Zarnekow, R. (2015). Success factors of cloud business models. Proceedings of the 23rd European Conference on Information Systems, Münster: Germany

Lambert, S. (2006a). A business model research schema. BLED 2006 Proceedings, Bled: Slovenia.

Lambert, S. (2006b). "Do We Need a "Real" Taxonomy of e-Business Models?" 06-6.

Lambert, S. (2015). The Importance of Classification to Business Model Research. Journal of Business Models, 3(1), 49-61. https://doi.org/10.5278/ojs.jbm.v3i1.1045

Lambert, S., \& Montemari, M. (2017). Business Model Research: From Concepts to Theories. International Journal of Business and Management, 12(11). https://doi.org/10.5539/ijbm.v12n11p41.

Lambert, S. C., \& Davidson, R. A. (2013). Applications of the business model in studies of enterprise success, innovation and classification: An analysis of empirical research from 1996 to 2010. European Management Journal, 31(6), 668-681. https://doi.org/ 10.1016/j.emj.2012.07.007

Lee, A. S., \& Baskerville, R. L. (2012). Conceptualizing Generalizability: New Contributions and a Reply. MIS Quarterly: Management Information Systems, 36(3), 749-761. https://doi.org/ $10.2307 / 41703479$

Leedy, P. D., \& Ormrod, J. E. (2014). Practical Research: Planning and Design, Pearson.

Lembcke, T.-B., Herrenkind, B., Willnat, M., Bührke, J., \& Nastjuk, I. (2020). Driving Future Mobility by Shared Mobility: A Taxonomy of Ridesharing Business Models. Proceedings of the 41st International Conference on Information Systems, India.

Levy, Y., \& Ellis, T. (2006). A Systems Approach to Conduct an Effective Literature Review in Support of Information Systems Research. International Journal of an Emerging Transdiscipline, 9, 181-212. https://doi.org/10.28945/479

Lüdeke-Freund, F., Carroux, S., Joyce, A., Massa, L., \& Breuer, H. (2018). The Sustainable Business Model Pattern Taxonomy 45 Patterns to Support Sustainability-Oriented Business Model Innovation. Sustainable Production and Consumption, 15, 145162. https://doi.org/10.1016/j.spc.2018.06.004
Lund, M. (2013). Innovating a Business Model for Services with Storytelling. In: C. Emmanouilidis, M. Taisch \& D. Kiritsis (eds.), Advances in Production Management Systems. Competitive Manufacturing for Innovative Products and Services. Berlin, Heidelberg: Springer Berlin Heidelberg, pp. 677-684.

Maechler, M., Rousseeuw, P., Struyf, A., Hubert, M., \& Hornik, K. (2019). cluster: Cluster Analysis Basics and Extensions. R package version 2.0.7-1. https://cran.r-project.org/web/packages/clust er/cluster.pdf.

Magretta, J. (2002). Why Business Models Matter. Harvard Business Review, 80(5), 86-92, 133.

Marradi, A. (1990). Classification, typology, taxonomy. Quality \& Quantity, 24(2), 129-157. https://doi.org/10.1007/BF00209548

Massa, L., Tucci, C. L., \& Afuah, A. (2017). A critical assessment of business model research. Academy of Management Annals, 11(1), 73-104. https://doi.org/10.5465/annals.2014.0072

McKelvey, B. (1978). Organizational Systematics: Taxonomic Lessons from Biology. Management Science, 24(13), 1428-1440. https:// doi.org/10.1287/mnsc.24.13.1428

Möller, F., Bauhaus, H., Hoffmann, C., Niess, C., \& Otto, B. (2019). Archetypes of Digital Business Models in Logistics Start-Ups. Proceedings of the 27th European Conference on Information Systems, Uppsala and Stockholm: Sweden.

Möller, F., Haße, H., Azkan, C., van der Valk, H., \& Otto, B. (2021). Design of Goal-Oriented Artifacts from Morphological Taxonomies: Progression from Descriptive to Prescriptive Design Knowledge. Proceedings of the 16th International Conference on Wirtschaftsinformatik, Essen: Germany (Digital).

Möller, F., Stachon, M., Hoffmann, C., Bauhaus, H., \& Otto, B. (2020). Data-Driven Business Models in Logistics: A Taxonomy of Optimization and Visibility Services. Proceedings of the 53rd Hawaii International Conference on System Sciences, Hawaii: USA.

Morris, M., Schindehutte, M., \& Allen, J. (2005). The Entrepreneur's Business Model: Toward a Unified Perspective. Journal of Business Research, 58(6), 726-735. https://doi.org/10.1016/j.jbusr es.2003.11.001

Muntermann, J., Nickerson, R., \& Varshney, U. (2015). Towards the Development of a Taxonomic Theory. Proceedings of the 21st Americas Conference on Information Systems, Puerto Rico.

Nagel, E., \& Kranz, J. (2020). Smart City Applications on the Blockchain: Development of a Multi-layer Taxonomy. In H. Treiblmaier \& T. Clohessy (Eds.), Blockchain and Distributed Ledger Technology Use Cases: Applications and Lessons Learned (pp. 201-226). Springer International Publishing.

Nagel, E., Kranz, J., Sandner, P., \& Hopf, S. (2019). How Blockchain Facilitates Smart City Applications-Development of A MultiLayer Taxonomy. Proceedings of the 27th European Conference on Information Systems, Uppsala and Stockholm: Sweden.

Nielsen, C., Lund, M., Montemari, M., Paolone, F., Massaro, M., \& Dumay, J. (2018). Business Models: A Research Overview. London: Routledge.

Nickerson, R. C., Varshney, U., \& Muntermann, J. (2013). A Method for Taxonomy Development and its Application in Information Systems. European Journal of Information Systems, 22(3), 336359. https://doi.org/10.1057/ejis.2012.26

Niederman, F., \& March, S. (2019). The "Theoretical Lens" Concept: We All Know What it Means, but do We All Know the Same Thing? Communications of the Association for Information Systems, 44(1), 1-33. https://doi.org/10.17705/1CAIS.04401

Notheisen, B., Willrich, S., Diez, M., \& Weinhardt, C. (2019). Requirement-driven Taxonomy Development - A Classification of Blockchain Technologies for Securities Post-Trading. Proceedings of the 52nd Hawaii International Conference on System Sciences, Hawaii: USA.

Oberländer, A. M., Lösser, B., \& Rau, D. (2019). Taxonomy research in information systems: A systematic assessment. Proceedings of 
the 27th European Conference on Information Systems, Uppsala and Stockholm: Sweden.

Österle, H., \& Otto, B. (2010). Consortium research. Business and Information Systems Engineering, 2(5), 283-293.

Osterwalder, A. (2004). The Business Model Ontology: A Proposition in a Design Science Approach. Dissertation.

Osterwalder, A., \& Pigneur, Y. (2013). Business Model Generation: A Handbook for Visionaries, Game Changers, and Challengers. Wiley.

Osterwalder, A., Pigneur, Y., \& Tucci, C. L. (2005). Clarifying Business Models: Origins, Present, and Future of the Concept. Communications of the Association for Information Systems, 16, 1-25. https://doi.org/10.17705/1CAIS.01601

Otto, B., Bärenfänger, R., \& Steinbuß, S. (2015). Digital Business Engineering: Methodological Foundations and first Experiences from the Field. 28th Bled eConference, Bled: Slovenia, pp. 58-76.

Passlick, J., Dreyer, S., Olivotti, D., Grützner, L., Eilers, D., \& Breitner, M. H. (2021). Predictive maintenance as an internet of things enabled business model: A taxonomy. Electronic Markets 31(1), . https://doi.org/10.1007/s12525-020-00440-5

Pateli, A. G., \& Giaglis, G. M. (2004). A Research Framework for Analysing eBusiness Models. European Journal of Information Systems, 13(4), 302-314. https://doi.org/10.1057/palgrave.ejis. 3000513

Paukstadt, U., Gollhardt, T., Blarr, M., Chasin, F., \& Becker, J. (2019a). A Consumer-oriented Smart Energy Business Model Taxonomy. Proceedings of the Twenty-Seventh European Conference on Information Systems, Uppsala, Sweden.

Paukstadt, U., Strobel, G., \& Eicker, S. (2019b). Understanding services in the era of the internet of things: a smart service taxonomy. Proceedings of the Twenty-Seventh European Conference on Information Systems, Uppsala, Sweden.

Peffers, K., Rothenberger, M., Tuunanen, T., \& Vaezi, R. (2012). Design Science Research Evaluation. In: K. Peffers, M. Rothenberger and B. Kuechler (eds.), Design Science Research in Information Systems. Advances in Theory and Practice. Berlin, Heidelberg: Springer Berlin Heidelberg, pp. 398-410.

Perscheid, G., Ostern, N., \& Moormann, J. (2020). Towards a taxonomy of decentralized platform-based business models. Proceedings of the 28th European Conference on Information Systems, An Online AIS Conference.

Punj, G., \& Stewart, D. W. (1983). Cluster Analysis in Marketing Research: Review and Suggestions for Application. Journal of Marketing Research, 20(2), 134-148. https://doi.org/10.2307/ 3151680

Randolph, J. J. (2009). A Guide to Writing the Dissertation Literature Review. Practical Assessment, Research \& Evaluation, 14(13), 1-13. https://doi.org/10.7275/b0az-8t74

Rappa, M. A. (2004). The Utility Business Model and the Future of Computing Services. IBM Systems Journal, 43(1), 32-42.

Reuver, M. de, Sørensen, C., \& Basole, R. C. (2018). The Digital Platform: A Research Agenda. Journal of Information Technology, 33(2), 124-135. https://doi.org/10.1057/s41265-016-0033-3

Remane, G., Hanelt, A., Nickerson, R., \& Kolbe, L., M. (2017a). Discovering Digital Business Models in Traditional Industries. Journal of Business Strategy, 38(2), 41-51. https://doi.org/10. 1108/JBS-10-2016-0127

Remane, G., Hanelt, A., Tesch, J., \& Kolbe, L., M. (2017b). The business model pattern database - a tool for systematic business model innovation. International Journal of Innovation Management, 21(1). https://doi.org/10.1142/S1363919617500049?src= recsys.

Remane, G., Nickerson, R. C., Hanelt, A., Tesch, J. F., \& Kolbe, L. M. (2016). A Taxonomy of Carsharing Business Models.
Proceedings of the 37th International Conference on Information Systems, Dublin: Ireland.

Rich, P. (1992). The Organizational Taxonomy: Definition and Design. The Academy of Management Review, 17(4), 758-781. https:// doi.org/10.2307/258807

Ritchey, T. (1998). General morphological analysis: A general method for non-quantified modelling.16th Euro Conference on Operational Analysis, Brussels: Belgium.

Ritter, T., \& Lettl, C. (2018). The wider implications of business-model research. Long Range Planning, 51(1), 1-8. https://doi.org/10. 1016/j.lrp.2017.07.005

Rudtsch, V., Gausemeier, J., Gesing, J., Mittag, T., \& Peter, S. (2014). Pattern-based Business Model Development for Cyber-Physical Production Systems. Procedia CIRP, 25, 313-319. https://doi. org/10.1016/j.procir.2014.10.044

Sabatier, V., Mangematin, V., \& Rousselle, T. (2010). From Recipe to Dinner: Business Model Portfolios in the European Biopharmaceutical Industry. Long Range Planning, 43(2), 431-447. https:// doi.org/10.1016/j.lrp.2010.02.001

Saldaña, J. (2015). The coding manual for qualitative researchers. Sage.

Sarkintudu, S. M., Ibrahim, H. H., \& Abdwahab, A. B. (2018). Taxonomy development of Blockchain platforms: Information systems perspectives. AIP Conference Proceedings, 2016(1) https://doi. org/10.1063/1.5055532.

Seddon, P. B., Lewis, G. P., Freeman, P., \& Shanks, G. (2004). The Case for Viewing Business Models as Abstractions of Strategy. Communications of the Association for Information Systems, 13(1), 427-442. https://doi.org/10.17705/1CAIS.01325

Schoormann, T., Behrens, D., Fellmann, M., \& Knackstedt, R. (2021). On Your Mark, Ready, Search: A Framework for Structuring Literature Search Strategies in Information Systems. Proceedings of the 16th International Conference on Wirtschaftsinformatik, Essen: Germany (Digital).

Schüritz, R., Seebacher, S., \& Dorner, R. (2017). Capturing Value from Data: Revenue Models for Data-Driven Services. Proceedings of the 50th Hawaii International Conference on System Sciences, Hawaii: USA.

Shafer, S. M., Smith, H. J., \& Linder, J. C. (2005). The Power of Business Models. Business Horizons, 48(3), 199-207. https://doi.org/ 10.1016/j.bushor.2004.10.014

Sipe, L. R., \& Ghiso, M. P. (2004). Developing Conceptual Categories in Classroom Descriptive Research: Some Problems and Possibilities. Anthropology \& Education Quarterly, 35(4), 472-485.

Spieth, P., Schneckenberg, D., \& Ricart, J. E. (2014). Business model innovation - state of the art and future challenges for the field. R\&D Management, 44(3), 237-247. https://doi.org/10.1111/ radm.12071

Staub, N., Haki, K., Aier, S., \& Winter, R. (2021). Taxonomy of Digital Platforms: A Business Model Perspective. Proceedings of the 54th Hawaii International Conference on System Sciences, Hawaii: USA.

Szopinski, D., Schoormann, T., John, T., Knackstedt, R., \& Kundisch, D. (2017). How Software Can Support Innovating Business Models: A Taxonomy of Functions of Business Model Development Tools. Proceedings of the 23rd Americas Conference on Information Systems, Boston: USA.

Szopinski, D., Schoormann, T., John, T., Knackstedt, R., \& Kundisch, D. (2019a). Software tools for business model innovation: Current state and future challenges. Electronic Markets, 30(3). https://doi.org/10.1007/s12525-018-0326-1

Szopinski, D., Schoormann, T., \& Kundisch, D. (2019b). Because your taxonomy is worth it: Towards a framework for taxonomy evaluation. Proceedings of the Twenty-Seventh European Conference on Information Systems, Uppsala, Sweden. 
Szopinski, D., Schoormann, T., \& Kundisch, D. (2020). Visualize Different: Towards Researching the Fit Between Taxonomy Visualizations and Taxonomy Tasks. Proceedings of the 15th International Conference on Wirtschaftsinformatik, Potsdam: Germany.

Täuscher, K., \& Laudien, S. (2017). Uncovering the Nature of Platform-based Business Models: An Empirical Taxonomy. Proceedings of the 50th Hawaii International Conference on System Sciences, Hawaii: USA.

Teece, D. J. (2010). Business Models, Business Strategy and Innovation. Long Range Planning, 43(2-3), 172-194. https://doi.org/ 10.1016/j.lrp.2009.07.003

Teece, D. J. (2018). Business Models and Dynamic Capabilities. Long Range Planning, 51(1), 40-49. https://doi.org/10.1016/j.lrp. 2017.06.007

Thiebes, S., Toussaint, P. A., Ju, J., Ahn, J.-H., Lyytinen, K., \& Sunyaev, A. (2020). Valuable genomes: Taxonomy and archetypes of business models in direct-to-consumer genetic testing. Journal of Medical Internet Research, 22(1). https://doi.org/10.2196/14890.

Timmers, P. (1998). Business Models for Electronic Markets. Electronic Markets, 8(2), 3-8. https://doi.org/10.1080/1019678980 0000016

Tönnissen, S., Beinke, J. H., \& Teuteberg, F. (2020). Understanding token-based ecosystems - a taxonomy of blockchain-based business models of start-ups. Electronic Markets, 30(2), 307-323. https://doi.org/10.1007/s12525-020-00396-6

Veit, D., Clemons, E., Benlian, A., Buxmann, P., Hess, T., Kundisch, D., Leimeister, J. M., Loos, P., \& Spann, M. (2014). Business Models: An Information Systems Research Agenda. Business and Information Systems Engineering, 6(1), 45-53. https://doi. org/10.1007/s12599-013-0308-y

Vorbohle, C., Szopinski, D., \& Kundisch, D. (2021). Toward Understanding the Complexity of Business Models - A Taxonomy of Business Model Dependencies. Proceedings of the 29th European Conference on Information Systems, Marrakesh: Morocco.

Ward, J. H. (1963). Hierarchical Grouping to Optimize an Objective Function. Journal of the American Statistical Association, 58(301), 236-244. https://doi.org/10.1080/01621459.1963.10500 845

Weber, M. (1949). On The Methodology of the Social Sciences (1st Edition). Illinois: USA: The Free Press.

Webster, J., \& Watson, R. T. (2002). Analyzing the Past to Prepare for the Future: Writing a Literature Review. MIS Quarterly: Management Information Systems, 26(2), pp. xiii-xxiii.
Weking, J., Hein, A., Böhm, M., \& Krcmar, H. (2018a). A Hierarchical Taxonomy of Business Model Patterns. Electronic Markets, 30(3). https://doi.org/10.1007/s12525-018-0322-5

Weking, J., Mandalenakis, M., Hein, A., Hermes, S., Böhm, M., \& Krcmar, H. (2020a). The impact of blockchain technology on business models - a taxonomy and archetypal patterns. Electronic Markets, 30(2), 285-305. https://doi.org/10.1007/ s12525-019-00386-3

Weking, J., Stöcker, M., Kowalkiewicz, M., Böhm, M., \& Krcmar, H. (2018b). Archetypes for Industry 4.0 business model innovations. 24th Americas Conference on Information Systems (AMCIS 2018), New Orleans: USA.

Weking, J., Stöcker, M., Kowalkiewicz, M., Böhm, M., \& Krcmar, H. (2020b). Leveraging industry $4.0-$ A business model pattern framework. International Journal of Production Economics (225) https://doi.org/10.1016/j.ijpe.2019.107588.

Wulf, J., \& Blohm, I. (2020). Fostering Value Creation with Digital Platforms: A Unified Theory of the Application Programming Interface Design. Journal of Management Information Systems, 37(1), 251-308. https://doi.org/10.1080/07421222.2019.1705514

Wulfert, T., Seufert, S., \& Leyens, C. (2021). Developing MultiSided Markets in Dynamic Electronic Commerce Ecosystems - Towards a Taxonomy of Digital Marketplaces. Proceedings of the 54th Hawaii International Conference on System Sciences, Hawaii: USA, pp. 6133-6142.

Zhang, L., Cushing, R., Gommans, L., de Laat, C., \& Grosso, P. (2019). Modeling of collaboration archetypes in digital market places. IEEE Access, 7, 102689-102700.

Zott, C., Amit, R., \& Massa, L. (2010). The Business Model: Theoretical Roots, Recent Developments, and Future Research. Working paper WP-862, IESE Business School - University of Navarra (ed.).

Zott, C., Amit, R., \& Massa, L. (2011). The Business Model: Recent Developments and Future Research. Journal of Management, 37(4), 1019-1042. https://doi.org/10.1177/0149206311406265

Publisher's Note Springer Nature remains neutral with regard to jurisdictional claims in published maps and institutional affiliations. 